\title{
Repositioning postnatal care in a high HIV environment: Swaziland
}

Charlotte E. Warren

Population Council

Rachel Shongwe

Allen Waligo

Mohammed Mahdi

Goldy Mazia

See next page for additional authors

Follow this and additional works at: https://knowledgecommons.popcouncil.org/departments_sbsr-hiv

Part of the Demography, Population, and Ecology Commons, Health Policy Commons, Immune System Diseases Commons, International Public Health Commons, Maternal and Child Health Commons, Medicine and Health Commons, Public Health Education and Promotion Commons, Virus Diseases Commons, and the Women's Health Commons How does access to this work benefit you? Let us know!

\section{Recommended Citation}

Warren, Charlotte E., Rachel Shongwe, Allen Waligo, Mohammed Mahdi, Goldy Mazia, and Indira Narayanan. 2008. "Repositioning postnatal care in a high HIV environment: Swaziland," Horizons Final Report. Washington, DC: Population Council. 


\section{Authors}

Charlotte E. Warren, Rachel Shongwe, Allen Waligo, Mohammed Mahdi, Goldy Mazia, and Indira Narayanan 


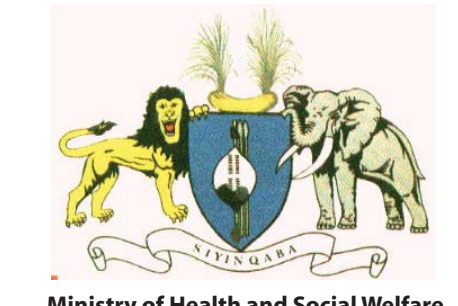

Ministry of Health and Social Welfare Government of Kingdom of Swaziland

\section{Repositioning Postnatal Care in a High HIV Environment: Swaziland}
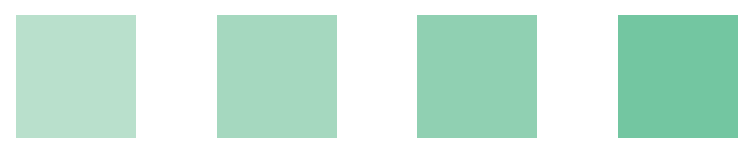

Horizons Program/Population Council

Central Statistical Office

\section{Elizabeth Glaser Pediatric AIDS Foundation}

BASICS

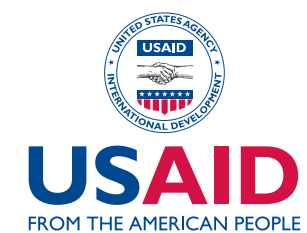

\section{Hgrizons 8BASICS}

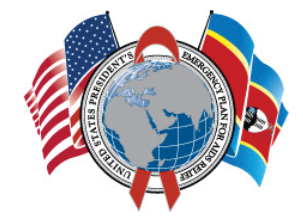

(2) Population Council

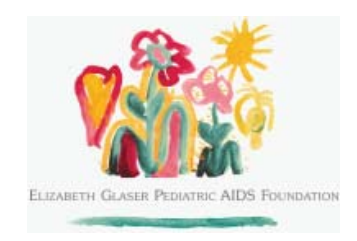




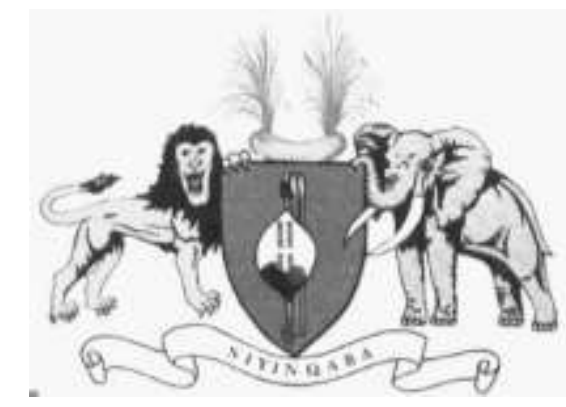

Ministry of Health and Social Welfare

Government of Kingdom of Swaziland

\title{
Repositioning Postnatal Care in a High HIV Environment: Swaziland
}

\author{
Charlotte Warren, Population Council; \\ Rachel Shongwe, Central Statistical Office; \\ Allen Waligo and Mohammed Mahdi, \\ Elizabeth Glaser Pediatric AIDS Foundation; and \\ Goldy Mazia and Indira Narayanan, BASICS
}


This study was supported by the Horizons Program, which is implemented by the Population Council in collaboration with the International Center for Research on Women, International HIV AND AIDS Alliance, PATH, Tulane University, Family Health International, and Johns Hopkins University. Horizons is funded by the President's Emergency Plan for AIDS Relief (1) through the U.S. Agency for International Development, under the terms of HRN-A-00-9700012-00. The opinions expressed herein are those of the authors and do not necessarily reflect the views of the U.S. Agency for International Development.

\section{(2) Population Council Horizons

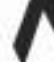

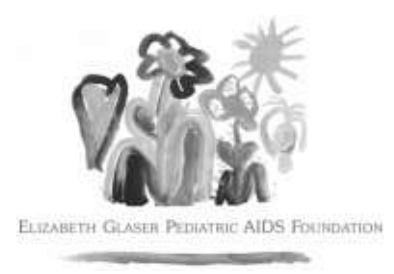

The Elizabeth Glaser Pediatric AIDS Foundation (The Foundation) is a recognized global leader in the fight against pediatric AIDS. Since its inception in 1988 as a U.S.-based non-profit 501 (c) (3), the Foundation has been at the global forefront of the fight to prevent pediatric HIV infection and to eradicate pediatric AIDS through research, advocacy, and prevention and treatment programs. The Foundation provided financial and technical support to this study. The financial support was provided to Population Council through the sub-agreement number CTA-0101-42-307-05. The sub-award was made under the authority provided to Elizabeth Glaser Pediatric AIDS Foundation USAID Cooperative Agreement No. GPH-A-00-02-00011-00), titled "Call to Action Project.." seeks to improve the well-being and reproductive health of current and future generations around the world and to help achieve a humane, equitable, and sustainable balance between people and resources. The Council conducts biomedical, social science, and public health research and helps build research capacities in developing countries. Established in 1952, the Council is governed by an international board of trustees. Its New York headquarters supports a global network of regional and country offices.

\section{BASICS}

BASICS (Basic Support for Institutionalizing Child Survival), is a global project to assist developing countries in reducing infant and child mortality through the implementation of proven health interventions. BASICS is funded by the U.S. Agency for International

Development (contract no. GHA-I-00-04-00002-00) and implemented by the Partnership for Child Health Care, Inc., comprised of the Academy for Educational Development, John Snow, Inc., and Management Sciences for Health. Subcontractors include the Manoff Group, Inc., PATH, and Save the Children Federation, Inc.

\section{Central Statistics Office Swaziland}

The Central Statistical Office (CSO) of Swaziland is a government department within the Ministry of Economic Planning and Development. The main function of the CSO is to compile statistical information for use by government and other development partners. At the request of the Population Council, CSO provided in-country technical support to assist in the implementation of the research component of the study.

(C)2008, The Population Council, Inc.

Published in February 2008.

Suggested citation: Warren, Charlotte, Rachel Shongwe, Allen Waligo, Mohammed Mahdi, Goldy Mazia, and Indira Narayanan. 2008. "Repositioning postnatal care in a high HIV environment: Swaziland," Horizons Final Report. Washington, DC:

Population Council.

This document may be reproduced in whole or in part without permission of the Population Council and partners provided full source citation is given and the reproduction is not for commercial purposes. 


\section{Acknowledgements}

The Ministry of Health and Social Welfare would like to thank those who made this operations research study possible. Work of this nature would not have been possible without the invaluable hard work and commitment of the health providers and social scientists that formed field teams to collect data. Special thanks go to all the pregnant women and postpartum women who participated in the study; without them the research would not have been possible.

Gratitude goes to the Central Statistics Office, specifically Rachel Shongwe and Nelisiwe Dlamini for the coordination of the training of data collectors and the field work, and to Phumuzile Mabuza and Bonsile Nhlabatsi of the Sexual and Reproductive Unit in the Ministry of Health and Social Welfare for facilitating the study. In addition we would like to thank Peggy Chibuye (Country Director for EGPAF 2004 - 2007) for her energy and support in getting the project off the ground.

Special recognition goes to the BASICS Regional trainers, Dr. Bongi Nzama and Ms. Nokuzola Mzolo from South Africa, and to the BASICS local coordinator/trainer, Ms. Prisca Khumalo, whose hard work and commitment contributed enormously to make the repositioning of postnatal care in Swaziland possible.

We would also like to recognize the financial and technical support from United States Agency for International Development (USAID) through Elizabeth Glaser Paediatric AIDS Foundation (EGPAF), Horizons/Population Council, and Basics Support for Institutionalising Child Survival (BASICS).
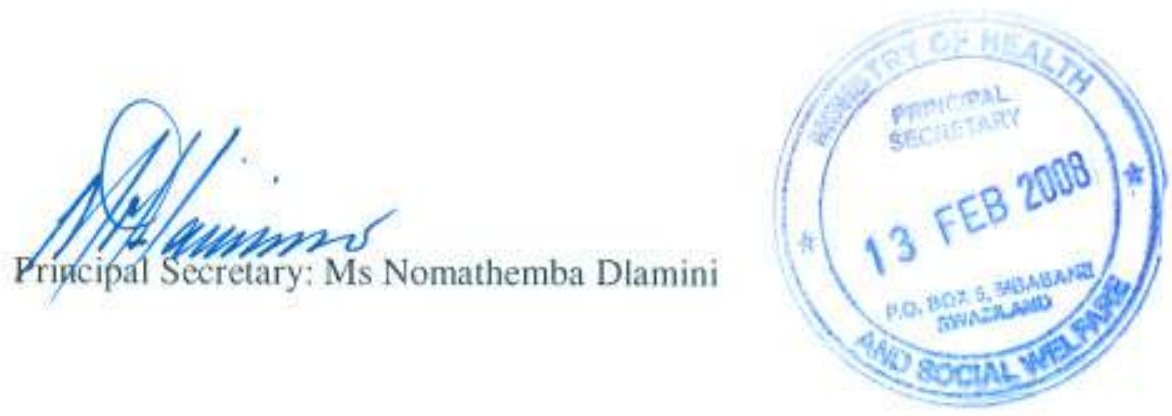



\section{Table of Contents}

\section{Acronyms or Abbreviations}

Executive Summary 1

$\begin{array}{ll}\text { Introduction } & 7\end{array}$

Addressing postnatal care $\quad 8$

Study Objectives and Methods $\quad 11$

$\begin{array}{ll}\text { Study objectives } & 11\end{array}$

$\begin{array}{ll}\text { Study design } & 11\end{array}$

Data collection $\quad 12$

$\begin{array}{ll}\text { Intervention } & 15\end{array}$

$\begin{array}{ll}\text { Postnatal care package } & 15\end{array}$

$\begin{array}{ll}\text { Training } & 16\end{array}$

$\begin{array}{ll}\text { Results of supervision activities } & 19\end{array}$

$\begin{array}{ll}\text { Sociodemographic characteristics of respondents } & 21\end{array}$

\section{$\begin{array}{ll}\text { Key Findings } & 23\end{array}$}

Facility preparedness to offer the new postnatal package 23

Provider knowledge of maternal and newborn health 24

Health provider knowledge of pre-discharge care and maternal and newborn essential care $\quad 24$

$\begin{array}{ll}\text { Quality of care observed through client-provider interactions } & 27\end{array}$

$\begin{array}{ll}\text { The postnatal period } & 29\end{array}$

Experience of postpartum women $\quad 33$

Infant feeding practices $\quad 34$

Follow-up care for mother and infant $\quad 36$

HIV testing and disclosure $\quad 40$

$\begin{array}{ll}\text { Family planning } & 41\end{array}$ 
$\begin{array}{ll}\text { Discussion } & 46\end{array}$

$\begin{array}{ll}\text { Maternal and newborn health } & 46\end{array}$

$\begin{array}{ll}\text { Family planning } & 49\end{array}$

$\begin{array}{ll}\text { Service delivery } & 49\end{array}$

$\begin{array}{ll}\text { Scale up } & 50\end{array}$

$\begin{array}{ll}\text { Recommendations } & 50\end{array}$

$\begin{array}{ll}\text { References } & 53\end{array}$ 


\section{Acronyms or Abbreviations}

AIDS

ANC

ART

BASICS

$\mathrm{BF}$

C\&T

CTX

CSO

DHS

EGPAF

FP

HIV

HTSP

IATT

IEC

$\mathrm{MCH}$

$\mathrm{MNH}$

MOHSW

OR

PHU

PMTCT

PNC

PP

$\mathrm{RH}$

TB

USAID

VCT

WHO
Acquired Immune Deficiency Syndrome

Antenatal Care

Antiretroviral Therapy

Basic Support for Institutionalizing Child Survival

Breastfeeding

Counseling and Testing

Cotrimoxazole

Central Statistics Office

Demographic Health Survey

Elisabeth Glaser Pediatric AIDS Foundation

Family Planning Human Immunodeficiency Virus

Healthy Timing and Spacing of Pregnancies Interagency Task Team (for PMTCT) Information, Education, and Communication Maternal and Child Health Maternal and Newborn Health Ministry of Health and Social Welfare

Operations Research Public Health Unit Prevention of Mother-to-Child Transmission Postnatal Care Postpartum Reproductive Health Tuberculosis

United States Agency for International Development Voluntary Counseling and Testing World Health Organization 



\section{Executive Summary}

Progress has been made in scaling up national programs for prevention of mother-to-child transmission (PMTCT) of HIV. Integrated antenatal care and PMTCT services provide an entry point for pregnant women to be tested for HIV and to ensure ARV prophylaxis for women testing positive during the last trimester of pregnancy and early labor, and for their infants after birth. However, one of the main challenges for PMTCT programs is the follow-up of mothers and infants after delivery.

Very little attention has been given to the early postnatal period (from birth to the end of the first week), although this is the most vulnerable time for the health of the mother and infant. Most deaths of newborns and mothers occur within the first hours or days after delivery (Lawn et al. 2005, WHO 2004). There is increasing evidence that maternal deaths related to HIV are rising (Gray and McIntyre 2005, McIntyre 2005, Lewis 2004). However, the neonatal period of the first four weeks of life is unique; although HIV infection in the mother will impact the health of the baby, practically all neonatal deaths in this period are due to non-HIV causes. This highlights the need to address the quality of basic maternal and newborn care with which PMTCT programs need to link.

Recognizing the need to improve the care and follow up of mothers and infants in the postnatal period, the Swaziland Ministry of Health and Social Welfare (MOHSW), with support from the Horizons Program of Population Council, the Elizabeth Glaser Pediatric AIDS Foundation (EGPAF), Basics Support for Institutionalising Child Survival (BASICS), and the Central Statistics Office (CSO), carried out an operations research project to reposition postnatal care (PNC) within the context of a high HIV environment. The objectives of the study were to determine if changes to the sexual and reproductive health guidelines on postnatal care would result in the timely and quality provision of key components of essential maternal and newborn care in the postnatal period, increase utilization of postnatal care services among all postpartum (PP) women, and improve the care and follow up of HIV-positive postpartum women and their infants.

\section{Methods}

Researchers used a pre- post-test design to assess the effectiveness of the new postnatal package of care in three maternity units and four public health units (PHU) or maternal and child health $(\mathrm{MCH})$ clinics in Manzini and Hhohho Regions, Swaziland. These sites were purposively selected because they were providing comprehensive PMTCT services supported by MOHSW and EGPAF.

In order to guide the design of the baseline assessment and intervention, field visits were undertaken by MOHSW, EGPAF, Horizons, and BASICS to learn what was actually happening at the facilities. This included gathering information about the organizational set-up of the PHU or $\mathrm{MCH}$, antenatal care (ANC), PMTCT, and family planning (FP) services. The research team discussed key issues such as: the pre-discharge examination(s); optimal timing of a postnatal visit; the content of the postnatal visit(s); and the clinic, outreach, and community components of postnatal care with health managers and partners to learn about the organization and management of existing services.

To assess outcome, the research team conducted a baseline survey that measured client and provider knowledge and behavior around postnatal care. The sample consisted of 356 postpartum women exiting the $\mathrm{MCH}$ clinics and 54 health care providers working in $\mathrm{MCH}$ and maternity units. The study also 
included assessing facility preparedness for providing an improved postnatal package and observing client-provider interactions in consultations during pregnancy and in the postnatal period.

\section{Intervention}

Based on these results, MOHSW and BASICS, with input from EGPAF, developed training materials and job aids on maternal and newborn health care in the postnatal period. The new package improves the timing and content of care for both mother and infant: in the postnatal ward before mothers leave the hospital; within one week (preferably within the first three days after the birth) in the MCH clinic and after six weeks in the MCH clinic. Following training of the core supervisory team with members from MOHSW and training institutions, nurse midwives, nurses, and nursing assistants from the selected sites were trained in the new package of care. Monthly supervisory visits were carried out by MOHSW and facilitated by the BASICS team. The intervention period was from July 2006 to May 2007.

Due to the short duration of the intervention, the focus of the capacity building emphasized the early postnatal period and the components of essential newborn care (Narayanan et al. 2004a) since they were the newest and most neglected areas. However, other important elements of service delivery were included. These were selected aspects of antenatal care, labor and delivery, family planning and PMTCT, and HIV and AIDS care and treatment. In addition, the health care providers themselves were stimulated by the training to update their own knowledge, and simple learning guides were provided for this purpose.

In Swaziland, 74 percent of deliveries take place in health facilities ${ }^{1}$. Therefore it was decided that this intervention would be primarily facility-based. An initial link with the community was established through the introduction of the new postnatal guidelines to the national trainers for Rural Health Motivators (RHM) who serve as community health workers. Discussions took place regarding the potential role of the RHMs and other community-based health workers in the new postnatal package.

To assess progress the researchers administered a follow-up survey to a sample of 346 postpartum women exiting the postnatal clinic, 92 mothers in the postnatal ward, and 35 health care providers. They also conducted observations of interactions between pregnant and postpartum women in the postnatal wards and $\mathrm{MCH}$ or PHU clinics.

\section{Key Findings}

The study confirms that the introduction of an improved postnatal package with revised timing and content provides key components of maternal, newborn, and HIV care, and increases the utilization of services among postpartum women and their infants. Postpartum women were three times more likely to attend PNC within one week of delivery post-intervention. An assessment of the quality of care during client-provider interactions for all postpartum women demonstrated a fourfold increase in the proportion that included all aspects of care: maternal and newborn health, counseling for HIV, family planning, and improved provider-client relationships.

\footnotetext{
${ }^{1}$ Preliminary findings from Swaziland DHS 2007
} 


\section{Facilities are prepared to provide new postnatal care package.}

An inventory checklist was used to generate a mean score of preparedness to assess how well each facility was equipped and staffed to carry out a new postnatal package. In each area assessed (staff trainings, services offered, equipment, drugs, and vaccines), results indicated that the selected sites generally had the capacity to provide postnatal care.

\section{Health provider knowledge increased in several areas.}

The knowledge and skills of health providers improved significantly post-intervention. For example, knowledge on how to maintain the baby's temperature at birth (dry baby immediately, wrap baby and cover head) improved significantly. In addition, there were notable increases in provider knowledge on danger signs in the newborn, which include signs of difficulty breathing, poor feeding, fever or hypothermia, abdominal distention and vomiting, convulsions, and signs of cord infection. There was an improvement in knowledge of newborn complications in areas such as identification of signs of asphyxia, and identification of danger signs. Health providers demonstrated significant improvements in their knowledge of counseling and support for infant feeding before discharge from the hospital. There were significant increases among health providers who reported that they would observe that proper feeding was established before discharging a mother.

However, there are still a number of gaps in providing comprehensive antenatal and postnatal care. For example, while there were increases in provider knowledge of actions to take for postnatal infection in the mother, there was no significant change in knowledge of signs of postpartum hemorrhage.

\section{More information was given to pregnant women during late pregnancy about the postnatal period.}

The quality of care observed during antenatal consultations (among women in the $8^{\text {th }}$ month of gestation) improved. Areas of improvement included advice on signs of onset of labor and danger signs in pregnancy and childbirth, birth planning and emergency preparedness, and instructions to return within one week after delivery. Limited improvements occurred in the area of advice given on danger signs in the postnatal period for mothers and newborns, infant feeding, and family planning. However, it is important to note that advice on infant feeding in the first ANC visit increased significantly from 35 percent at baseline to 63 percent at endline.

\section{Women and their babies received better postnatal care.}

Care during the postnatal period from birth to six weeks improved dramatically. Provider practice demonstrated a commitment to providing quality of care for mother and baby on both the postnatal wards and in the clinics. In the majority (93 percent) of provider-client interactions on the postnatal ward postpartum women were given a general examination. This included measuring their blood pressure (96 percent), temperature ( 89 percent), and pulse ( 75 percent); as well as the uterus being palpated (93 percent) and the breasts examined (96 percent). Newborns were examined in 89 percent of observations, including examination of the cord (96 percent). 
There were significant increases in providers counseling for maternal and newborn danger signs during the postnatal period both in the hospital before discharge and during follow-up visits. As a result of the change in the recommended timing of visits during the intervention, a significant proportion of postpartum women at endline visited the postnatal clinic earlier (within one week postpartum and many in the first three days) in comparison to baseline. Possible factors resulting in the above were (a) counseling in ANC of the importance of early postnatal care, and, probably of greater importance, (b) additional counseling and provision of a specific appointment for the visit at discharge of the mother and baby from the facility after delivery (observed being done by 82 percent of health providers). Later visits (2-6 weeks) also increased, indicating a higher proportion of repeat postnatal visits. Interviews with postpartum women confirmed these findings.

The results revolve around distinct components related to comprehensive postnatal care: maternal health, newborn health including infant feeding, HIV/PMTCT, client fertility intentions and uptake of family planning commodities, care and follow up, and acceptability of the new PNC. All components of quality of care for mother and newborn increased significantly over the study period. Provider performance regarding advice for components of essential newborn care such as temperature maintenance (46 percent) and cord care (62 percent) was only measured at endline.

\section{A higher proportion of postpartum women were breastfeeding post-intervention.}

Counseling on exclusive breastfeeding (BF) during the postnatal consultations improved dramatically from 18 percent to 79 percent. The low breastfeeding rates at baseline could have been due to the recommendation on replacement feeding for HIV-positive women; since HIV is highly prevalent, this could have been adopted by many women in Swaziland, and may have caused confusion among providers and families. This intervention resulted in increased breastfeeding rates and initiation during the first hour after birth. It is therefore important to emphasize that significantly more women were breastfeeding and initiating breastfeeding within an hour of birth at endline. There was a 40 percent increase in HIVpositive postpartum women and 50 percent increase in HIV-negative postpartum women who breastfed their babies within one hour of birth. Mixed feeding among HIV-positive women and replacement feeding in HIV-negative women reduced significantly.

\section{The strong PMTCT program maintained a high proportion of women testing for HIV and receiving ART.}

Given the emphasis of the MOHSW national PMTCT program, it is of no surprise that there continues to be a high ratio of pregnant women testing for HIV during ANC and receiving prophylaxis during pregnancy (AZT) and Nevirapine during early labor (90 percent), while the newborn receives Nevirapine at birth. However, the uptake of testing in the labor and postnatal ward can be attributed to the introduction of the new integrated PMTCT and maternal and newborn health (MNH) postnatal package.

\section{More women's partners were testing for HIV and sharing their results.}

There were significant increases in the number of partners who tested for HIV (from 28 percent to 56 percent) and shared their results (from 21 percent to 34 percent). 


\section{There was an increased use of care and support services by HIV-positive postpartum women and their infants.}

There was a significant increase in the proportion of both HIV-positive postpartum women and their infants starting Cotrimoxazole prophylaxis, from 47 percent to 65 percent and from 13 percent to 37 percent, respectively. After the intervention, health providers gave more information to HIV-positive women on the available care and support, specifically on food supplements, family planning, support groups, and community support. In addition, observations of the postnatal consultations demonstrated increased counseling on available services and risk factors for HIV and sexually transmitted infections (STIs). More providers confirmed that HIV-positive postpartum women received the relevant or appropriate follow-up care and treatment.

\section{More women were asked about family planning by health care providers.}

Many postpartum women are unaware of when they can become pregnant again after giving birth. On the question related to knowledge of when a woman could expect to get pregnant again, only 8 percent of all postpartum women interviewed at the clinic were able to give the correct answer of "any time after having sex." The majority of postpartum women interviewed said they did not intend to have another child. The proportion of HIV-positive postpartum women not wanting another child increased from 77 percent at baseline to 83 percent at endline. Among HIV-negative postpartum women, the increase was from 52 percent to 59 percent. For postpartum women who had given birth more than two weeks previous to the consultation, a substantial proportion of the interactions demonstrated an increase in the client being asked about her preferred method (from 32 percent at baseline to 82 percent at endline) and actually receiving her preferred method (from 28 percent at baseline to 70 percent at endline).

\section{The new postnatal package was well received by clients.}

Overall there were significant improvements in the acceptability of and satisfaction with the improved care among postpartum women, measured by how they were treated by providers in the postnatal clinic. Large increases of about 50 percent were seen in the number of providers ensuring privacy and assuring postpartum women of confidentiality. More postpartum women who had come in for a one-week check up were observed receiving a return appointment date for further follow up (from 86 percent at baseline to 93 percent at endline).

\section{Providers were receptive to new postnatal package.}

Generally health providers appreciated the early postnatal visit. Providers said that it was an "eye opener" to see that if the postpartum women were followed sooner, complications could be detected earlier. The early visit at one week enabled providers to reinforce feeding options and to encourage postpartum women of unknown HIV status to be counseled and tested. They were also better able to follow up with postpartum women who were HIV-positive. Health providers preferred providing integrated care to the mother and infant, which included FP, PNC, and infant immunizations. 


\section{Sustaining new PNC package requires addressing barriers.}

While the introduction of the intervention activities themselves was feasible, problems were encountered that may influence the clinics' capacity to implement and sustain the reorganized services. These include: trainer and staff turnover, inadequate logistics and budgetary planning, and insufficient involvement of key stakeholders. Emigration and attrition due to HIV and AIDS also undermine the workforce in the public sector in Swaziland (Kober 2006). Efforts to scale-up or replicate this model throughout the country and elsewhere in the southern African region must consider such resource issues during the planning and budgeting phase. 


\section{Introduction}

Swaziland continues to have one of the highest rates of HIV infection in the world, particularly among pregnant women, of whom an estimated 39 percent are HIV-positive (MOHSW 2006). The national population-based HIV rate among the reproductive age group (15 to 49 years) for men and women is among the highest in the world at 26 percent. Consequently, HIV infection remains a significant cause of infant morbidity and mortality. Approximately 17,000 HIV-exposed infants are delivered every year; HIV-exposed or infected infants have a high probability (50 percent) of dying in their first two years (MOHSW 2006). Moreover, Swaziland is one of ten countries with the worst increase in the mortality rate of children under age five (110 per 1,000 live births in 1990 compared to 160 per 1,000 live births in 2005) due to HIV and AIDS.

Since the inception and launch of the national prevention of mother-to-child transmission (PMTCT) program by the Swaziland Ministry of Health and Social Welfare (MOHSW) in 2003, phased integration of PMTCT activities into existing maternal and child health $(\mathrm{MCH})$ services has gained momentum. The Elizabeth Glaser Pediatric AIDS Foundation (EGPAF), through United States Agency for International Development (USAID) funding, and UNICEF were two of the partners to respond to the call to assist the Government to roll out the PMTCT program in accordance with the national PMTCT plan. EGPAF's support for PMTCT successfully expanded from three initial sites in July 2004 to 31 sites by March 2007.

Antenatal care (ANC) services are available in all primary health care facilities (clinics); 97 percent of all pregnant women in the country attend ANC at least once, and 74 percent deliver in health facilities (SDHS 2006-07). For HIV-positive women, integrated antenatal care and PMTCT services provide an entry point to ensure antiretroviral (ARV) prophylaxis for themselves during the last trimester of pregnancy, during early labor, and for their infants after birth. However, one of the main challenges for PMTCT programs is the follow-up of mothers and infants after delivery.

While PMTCT programs in theory support the fourth prong $^{2}$ of care and support for HIV-positive women and their families, there is limited care for postpartum ${ }^{3}$ women post-delivery; this misses an obvious opportunity to promote health and prolong their lives (Myer et al. 2005). Moreover, discussion about family planning and promotion of methods during the early postnatal period is not common (Rutenberg and Baek 2004). The reduction of unintended pregnancies is an important element of PMTCT, especially in high HIV prevalence countries. A study found that moderate decreases in unintended pregnancies, ranging from 5.6 percent to 3.8 percent, can result in the same number of prevented HIV infections as the use of Nevirapine (Sweat et al. 2001). Reynolds and Wilcher (2006) describe the prevention of unintended pregnancies as an "undervalued and little-used strategy."

Many PMTCT programs find implementation of any post-delivery interventions to be challenging. An evaluation of the UN-supported PMTCT pilot projects found that programs had difficulty following up with postpartum women after delivery, and thus recommended the establishment of postnatal follow-up protocols (Rutenberg et al. 2003). Moreover, it is difficult to provide continuous support for infant feeding and family planning in the postnatal period, as the vast majority of postpartum women are not

\footnotetext{
${ }^{2}$ Four prongs of PMTCT: 1) prevention of HIV infection; 2) prevention of unwanted/unplanned pregnancies; 3) prevention of HIV transmission to infant; and 4) follow-up care and support (WHO)

${ }^{3}$ For this document the term postpartum refers to the maternal elements and postnatal refers to both mother and baby. Generally the postnatal period refers up to the period following birth to six weeks. However given that many women do not return exactly at 6 weeks, this report covers women and their infants up to 10 weeks after birth.
} 
necessarily linked into the ANC/MCH system. Statistics are scarce regarding what happens to HIVpositive mothers and their infants between the time they are discharged and the time they return to the health facility for child health, family planning, or another pregnancy. In high HIV prevalence environments, there is a need to examine and address the content of care provided to postpartum women post-delivery, and to improve health facilities' ability to keep postpartum women linked into the health system.

Even where HIV and AIDS programs are comprehensive and include all four prongs of PMTCT, they generally do not adequately address the non-HIV aspects of care for all women and children. Thus, while PMTCT services may be linked to existing maternal and child health $(\mathrm{MCH})$ services, they do not verify or address the quality of the latter. Basic antenatal care services are readily available and accessed by the majority of women regardless of HIV status; fewer receive skilled care at birth, and even fewer receive postnatal care for themselves and their newborns. High rates of maternal mortality and the large number of neonatal deaths bear testimony to this. The neonatal period of the first four weeks of life is unique: although HIV infection in the mother will influence the outcome of the baby, practically all neonatal deaths (22/1000 births) in this period are due to non-HIV causes. This highlights the need to address the quality of basic maternal and newborn care.

This situation, coupled with evidence from several African studies (Gray and McIntyre 2005, McIntyre 2005, Lewis 2004, Department of Health, South Africa 2004) demonstrating that the mortality of HIVinfected postpartum women is high in the post-pregnancy period, prompted the MOHSW to improve the utilization of postnatal care and follow-up of both HIV-positive and HIV-negative mothers and their infants. The MOHSW was interested in changing the postnatal care guidelines to ensure targeted examinations of both mother and baby: in the postnatal ward before they leave the hospital; within one week (preferably within the first three days after the birth) in the MCH clinic, and at six weeks in the MCH clinic. The MOHSW subsequently requested EGPAF and the USAID Regional HIV and AIDS Program (for Southern Africa) to support operations research on the "Repositioning of Postnatal Care Services." USAID/RHAP accepted the MOHSW's request and invited the Horizons Program of the Population Council and EGPAF to undertake operations research in collaboration with the MOHSW, Central Statistics Office (CSO), and BASICS. BASICS provided technical assistance for the intervention.

The study commenced in early 2006 with the aim of repositioning and strengthening postnatal care (PNC), including enhanced care, treatment, and support for HIV-exposed infants, mothers, children, and families. It was anticipated that by improving the quality of postnatal care and by providing coverage early in the first week, the most common causes of death for the mother and baby would be addressed. Also, among other HIV and AIDS services, more infants born to HIV-positive mothers would receive ARV prophylaxis within three days of birth, and start Cotrimoxazole prophylaxis at six weeks. In addition, more mothers would receive early postnatal family planning services. HIV-positive mothers and exposed infants would be followed up in maternal and child clinics and referred as appropriate for further management. It was believed that this strategy would increase access of mother-baby pairs to care and treatment. HIV-negative women and those of unknown status would also benefit from quality postnatal services.

\section{Addressing Postnatal Care}

The issue of inadequate postnatal follow-up for all mothers and their infants is not unique to Swaziland. Indeed, it is widely acknowledged to be an acute problem in many sub-Saharan African countries. 
Traditionally, the strategies to reduce maternal and perinatal morbidity and mortality have focused on the pregnancy and delivery periods, and very little attention has been given to the postnatal period. The postnatal period (from birth to six weeks) is the most vulnerable time for the health of the mother and infant. Most deaths of newborns and mothers occur in the immediate postnatal period; for newborns, three-quarters of the deaths occur in the first week and of those, two-thirds occur in the first 24 hours (Lawn et al. 2005). Over 60 percent of maternal deaths occur in the first 48 hours after childbirth (WHO 2005), and therefore early detection and management of obstetric and neonatal complications is especially important within the first week after delivery. There is increasing evidence that maternal deaths related to HIV are rising and that AIDS has overtaken direct obstetric causes as the leading cause of maternal mortality in countries in southern Africa with high HIV prevalence (Gray and McIntyre 2005, McIntyre 2005, Lewis 2004). In South Africa, HIV and AIDS accounted for one-fifth of maternal deaths between 2002 and 2004 (Department of Health, South Africa 2003). In contrast, most infant deaths in the newborn period are still due to non HIV-related causes (sepsis, asphyxia, and prematurity). Although many HIVpositive women may not require special medical care in the postnatal period, the most common complications are those due to infections such as puerperal sepsis, infected episiotomies, urinary tract infections, pneumonia, tuberculosis, and other unusual infections. All these increase the chances of both HIV-positive and HIV-negative women dying.

In addition to the challenges presented by the HIV epidemic, inadequate knowledge among health service providers on the importance and timing of postnatal care has contributed to unnecessary loss of life. For a mother living with HIV, the postnatal period is an equally critical time to emphasize healthy behaviors and care; including early and exclusive breastfeeding, early postnatal family planning, partner testing and support, repeat CD4 testing, antiretroviral prophylaxis or treatment, and initiating Cotrimoxazole prophylaxis for her baby. Furthermore, early postnatal visits offer the opportunity to address the components of preventive essential newborn care and to identify any mothers and/or infants who are having problems and address them immediately.

Important strategies should therefore include good care at birth as well as improved care to cover the first week of life. This involves a careful assessment before the birth attendant leaves the mother after delivery at home or before discharge from a facility, early links with trained community health workers, early follow up with a skilled provider within three days, counseling of the mother and family in preventive care, and early identification of danger signs and timely and appropriate care seeking. In this context it becomes critical that the investment provided in PMTCT programs should not be lost to more common causes of death among newborns in the immediate postnatal period ${ }^{3}$ (Narayanan et al. 2004b). Timely and high quality postnatal coverage for the mother and the baby by a qualified health provider is an opportunity to address this critical period. Moreover the health provider can apply cost-effective preventive measures to identify and treat mothers and/or infants who are having problems, and to link the HIV-positive mother and her exposed infant to care and treatment services.

In Swaziland, care during the postnatal period for mother and baby was previously outlined in the sexual and reproductive health $(\mathrm{SRH})$ guidelines, which lack specific comprehensive recommendations on postnatal care, and only recommend that mothers return six weeks after delivery. Anecdotal reports suggested that although many postpartum women did return after six weeks to a health facility, these visits were mainly for child immunization and sometimes for family planning, rather than for targeted postnatal care and HIV-related services. In any case, the major postnatal problems for the mother and baby often take place during the first week after delivery. Furthermore, although the infant usually receives immunizations at around six weeks, they may be brought in by another family member, and if the mother does not choose to take up family planning, she will not be examined at all. Just prior to the 
study some facilities were encouraging HIV-positive postpartum women to come back after two weeks for discussion with the PMTCT counselor, who would mainly provide support for feeding. The mother was asked how she was feeling but was not given a physical checkup. Not all counselors had midwifery skills nor the appropriate equipment or resources for examinations, further highlighting the deficiency of quality postnatal care.

The Swaziland National Reproductive Health Strategy/Plan of Action developed with UNFPA in 2004 outlines Safe Motherhood as an important area. However the plan includes no reference to postnatal care at all. Guidelines for PMTCT were also developed in 2004 (MOHSW 2004) which make some reference to the postnatal period, but these are incomplete and do not provide a comprehensive package of postnatal care for all mothers and their newborns.

This study sought to determine if the MOHSW's proposed changes to the SRH guidelines on postnatal care and implementation of these guidelines resulted in the: 1) provision of the key components of essential maternal and newborn care in the postnatal period, 2) increased utilization of postnatal care services among all postpartum women, and 3) improved care and follow up of HIV-positive postpartum women and their infants. 


\section{Study Objectives and Methods}

\section{Study Objectives}

The study objectives were to:

- Document the types of service delivery modifications required to:

- Improve care and follow up of all postpartum women and their infants.

- Improve care and follow up of HIV-positive postpartum women and their infants.

- Improve referrals and linkages to HIV care and treatment service.

- Improve and sustain the continuum of care of all mothers recently delivered (linking to well-child care and family planning; keeping HIV-negative mothers negative and HIV-positive mothers healthy).

- Offer HIV counseling and testing (C\&T) to postpartum women of unknown HIV status.

- Measure the effect of implementing changes to the postnatal care policy guidelines on:

$\circ$ The quality of postnatal care for all women.

- The utilization of postnatal services by all postnatal mothers.

- The use of HIV care and support services by HIV-positive postpartum women and their infants.

- On the basis of the information generated by the study:

$\circ$ Revise postnatal guidelines,

- Print and distribute the revised guidelines,

- Promote their utilization to expand the focus of care and encourage early attendance at the postnatal clinic for mother/baby pairs.

\section{Study Design}

To guide the design of the baseline assessment and intervention, MOHSW facilitated field visits from EGPAF, Horizons, and BASICS so they could learn what was actually happening at the health facilities. This included learning about the organizational set up of $\mathrm{MCH}, \mathrm{ANC}, \mathrm{PMTCT}$, and family planning services. The research team discussed key issues such as the pre-discharge examination(s), optimal timing of a postnatal visit, content of the postnatal visit(s), and clinic, outreach, and community components of postnatal care with health managers and partners to learn about the organization and management of existing services. Meetings were held with health providers to understand their views about revising the postnatal visit and the support that they needed. At the pilot study sites discussions took place with community gatekeepers such as rural health motivators (RHM), pregnant women, and postpartum women who recently gave birth, about the acceptability of and potential obstacles to attending revised postnatal visit(s). The proposal was developed in discussion with MOHSW and USAID/RHAP, subsequently submitted to and reviewed by MOHSW in Swaziland, and granted ethical approval by the MOHSW.

The operations research was a quasi-experiment to evaluate the effectiveness of the new postnatal care service guidelines. The study population comprised pregnant and newly-delivered postpartum women attending ANC and PNC services at selected health facilities. The baseline and endline evaluations were cross sectional, and quantitative data were collected from four purposefully selected sites that were providing comprehensive PMTCT services supported by MOHSW and EGPAF. 


\section{Study sites}

The sites included Raleigh Fitkin Memorial (RFM) Hospital, Mankayane Government Hospital, and King Sobhuza II Public Health Unit in Manzini Region, and Mbabane Government Hospital and Public Health Unit in Hhohho Region. Each hospital had both public health units (PHU) or maternal and child health $(\mathrm{MCH})$ units and maternity units.

Although the study sites were purposefully selected, it was nonetheless thought that the results of the survey would give a general picture of the status of postnatal care, given that the catchment population of the sites covers a large proportion of the country - approximately 12,000 deliveries per year. According to the MOHSW records there were 13,663 facility deliveries in 2006. The Swaziland Demographic Health Survey 2007 estimates 25 percent of women give birth at home. Thus the estimate for all deliveries in 2006 is 17,120 (MOHSW 2007). Due to the high prevalence of pregnant women with HIV in Swaziland, it was assumed that approximately 40 percent of the study sample of postpartum women would be HIVpositive.

\section{Data Collection}

A set of similar data collection tools was used for the baseline and endline assessments. Data were collected in three different ways: (1) face-to-face interviews with postpartum women and health providers; (2) direct observation of client-provider interactions in the antenatal clinic, postnatal ward, and postnatal clinic; and (3) review of facilities' readiness, hospital records, and service statistics.

With the assistance of MOHSW, ten nurse/midwives were recruited for each phase of data collection. An additional group of ten experienced research assistants was also recruited to conduct face-to-face interviews with clients at endline. Training took place over one week and included mock interviews to practice using the tools.

Prior to baseline data collection the research tools were pre-tested at the Hlathikhulu Government Hospital, and changes were incorporated. The client questionnaire was also translated into Siswati. Data were collected in February and March 2006 for the baseline assessment and in May 2007 for the evaluation.

Informed consent was obtained from all respondents, who were assured that the information would be confidential prior to each interview. Supervisors checked all completed questionnaires for data quality and accuracy.

\section{Data collection tools}

\section{Face-to-face interviews}

a. Exit interviews with 300 postpartum women (120 HIV-positive women and $180 \mathrm{HIV}$-negative women): Short exit interviews were held with each consenting client to ascertain her perception of the competence of providers and her overall impression and understanding of the services received. Postpartum women with infants under 10 weeks old were asked about their experiences with post-delivery counseling, education, and physical examinations since birth. Client flow in the facilities and time spent with each provider was also assessed. At endline the MOHSW 
requested that a client exit interview from the postnatal ward as well as the postnatal clinic also be conducted to assess perceptions of the new postnatal package.

b. Interviews with 50 health care providers: Short structured interviews with health care providers assessed their training in and knowledge of ANC, childbirth, and the postnatal period, as well as their attitudes toward and satisfaction with the package. All health care providers at the antenatal, family planning, child welfare, and postnatal clinic in the PHU/MCH units and providers in labor, postnatal, and neonatal/baby wards at the hospitals who were on duty at the time of the survey were approached for an interview. None of the health care providers declined to be interviewed.

\section{Direct observation of 40-50 client-provider interactions}

Qualified nurse/midwives were trained to observe and record aspects of antenatal/postnatal consultations to measure provider competence and their ability to follow service provider guidelines for care using a standardized checklist. Client-provider interactions were observed for two groups of pregnant women: one for the first ANC visit and one for pregnant women in their last month of pregnancy. In addition, interactions were observed for all postpartum women from one week to ten weeks post-delivery (to include women who delayed accessing postnatal care at six weeks). To reach a meaningful measure of quality of care with a relatively small sample size, 12-24 client-provider interactions were expected to be observed in each category at each clinic. In response to a request from the MOHSW, a structured observation was carried out in the postnatal ward prior to discharge at endline.

\section{Review of facilities' readiness, hospital records, and service statistics}

a. Rapid unit assessment: Researchers examined available resources at baseline to understand the readiness of facilities to implement PNC, including: availability of equipment, commodities, test kits, stationary (client cards and notes), ARV drugs, and other medications. A check list was administered by qualified nurse /midwives to the unit in-charges. Seven units were assessed and included:

- Mbabane maternity unit and public health unit (2 separate tools)

- Mankayane maternity unit and public health unit (2 separate tools)

- Raleigh Fitkin maternity unit and maternal and child health unit (2 separate tools)

- King Sobhuza II public health unit (one tool used )

b. Review of in-patient notes: Partographs, doctor's notes, and operation notes for normal delivery and cesarean section were randomly selected and assessed for the quality of data recorded.

c. Review of service statistics: These included statistics measuring utilization of antenatal care, postnatal care, and family planning and PMTCT services over the project period 
Table 1 Summary of instruments used and sample sizes for baseline and endline

\begin{tabular}{|c|c|c|c|}
\hline Name of instrument & $\begin{array}{l}\text { Required minimum } \\
\text { sample size }\end{array}$ & Baseline & Endline \\
\hline $\begin{array}{l}\text { Postnatal clinic client exit interview } \\
\text { (between } 1 \text { week and } 10 \text { weeks after delivery) }\end{array}$ & 300 & 356 & 346 \\
\hline HIV-positive & 120 (30 from each site) & 114 & 136 \\
\hline HIV-negative & 180 (45 from each site) & 162 & 191 \\
\hline Unknown status $^{\dagger}$ & & 73 & 19 \\
\hline $\begin{array}{l}\text { Postnatal ward client exit interview } \\
\text { (within } 24 \text { hours) }\end{array}$ & 60 (20 from each site ) & - & 94 \\
\hline Provider interview & 50 (12 from each site) & 54 & 35 \\
\hline First ANC observation & 48 (12 from each site) & 49 & 38 \\
\hline Last ANC observation & 48 (12 from each site) & 50 & 37 \\
\hline Postnatal clinic observation & 48 (12 from each site) & 57 & 117 \\
\hline Postnatal ward observation & 60 (20 from each site ) & - & 28 \\
\hline Record review of normal deliveries & 60 (20 from each site ) & 61 & 62 \\
\hline Record review for $\mathrm{C} / \mathrm{S}$ deliveries & 60 (20 from each site ) & $40^{*}$ & 64 \\
\hline $\begin{array}{l}\text { Facility tool ( } 3 \text { public health units, } 1 \text { maternal and } \\
\text { child health unit and } 3 \text { maternity units) }\end{array}$ & 7 & 7 & 7 \\
\hline
\end{tabular}

$\dagger$ Postpartum women were interviewed as they left the facility

*At baseline caesarian sections (C/S) were not carried out at Mankanyane Hospital

\section{Data entry}

Data was entered using Epi Info and later converted to SPSS for analysis. Pearson's Chi square tests were used to determine the significance of the differences between the pre- and post-intervention results. A pvalue of less than 0.05 was used as the threshold for significance.

\section{Composite scores}

In a number of instances data were drawn from the client-provider observation tool, and mean scores were computed for each indicator and then aggregated across all indicators to give the composite score for quality of maternal and newborn health care given. Likewise data were also drawn from the provider interview and mean scores were computed to give a composite score for knowledge. This method was used to demonstrate overall improvements in care and knowledge rather than individual aspects. 


\section{Intervention}

The MOHSW, facilitated by BASICS, was responsible for implementing an intervention designed to provide quality postnatal care with an expanded focus on all aspects of essential care for all mothers and newborns and integration with HIV services. The design of the intervention was based on discussions with the MOHSW, site visits to the selected hospitals and public health units, EGPAF project reports, and the baseline assessment (February 2006). The intervention included training of health managers and providers on the improved postnatal care package, supervision, and the reorganization of services.

\section{Postnatal Care Package}

The new postnatal package introduces additional consultations as well as strengthens existing consultations that should be carried out for the mother and her baby during the postnatal period. These are: immediate care after birth, pre-discharge postnatal assessment on the postnatal ward (within 12 hours), an early follow up assessment within three days and/or seven days, and again at six weeks.

The design of the new and improved postnatal services stipulates that the mother and the newborn be cared for by the same health provider during the same consultation. That is, the mother and her newborn should be seen by the same health provider and all necessary services should be rendered at the same time (FP, PNC, PMTCT follow up, infant immunizations, and growth monitoring). The following were identified as the key situations for providing essential postnatal care (and linkages with HIV services):

- Normal deliveries in facilities

- Care after birth.

- Pre-discharge postnatal assessment: In most cases postpartum women are discharged within 12 hours of the birth.

o First follow-up assessment or visit within one week (preferably within three days).

○ Second follow-up visit at six weeks for mother and baby.

- Complicated deliveries in facilities

○ Care after birth and at pre-discharge.

- First follow-up assessment within one week and according to condition: i.e., weekly for the low birth weight baby until weight is adequate; at time of removal of stitches for the mother in case of surgery; after 2-3 days if treated for infection; and according to the need for specific care related to HIV.

O Other follow-up assessments/visits according to need.

○ Visit at six weeks for mother and baby.

- Home deliveries

$\circ$ Contact with a qualified health provider in the first 24- 48 hours for first assessment, care, and counseling.

o Repeat assessment/visit at the end of the first week or as advised by the health care provider.

$\circ$ Visit at six weeks for mother and baby.

Technical aids with the all the elements for each consultation depending on the timing were adapted and distributed to providers. 


\section{Training}

\section{Materials}

Most of the materials used for training in postnatal care were developed or adapted by BASICS. Other relevant materials developed by Saving Newborn Lives and the World Health Organization were also distributed by BASICS:

- Technical aids for hospital health workers (BASICS).

- Technical aids for PHUs and clinics (BASICS).

- PowerPoint presentation handouts (BASICS).

- Reference manuals (SNL, WHO).

- Recommended readings (BASICS publications, selected series from The Lancet, and documents on safe motherhood).

- Supervision tools (BASICS).

- Monitoring and evaluation tools (MOHSW and BASICS).

\section{Strategy}

The strategy developed by BASICS and MOHSW incorporated a four-step training approach:

1. Training of core supervisory team.

2. Training of staff from intervention sites.

3. Dissemination day for doctors working in obstetrics and pediatric departments.

4. Dissemination day for rural health motivator (RHM $)^{4}$ supervisors/trainers.

The first training session was delivered by the BASICS team ${ }^{5}$ to the core national supervisory team. Groups of staff from the intervention sites were trained in three further sessions (for midwives, nurses, and nursing assistants). BASICS trainers worked together with selected members of the core supervisory team to ensure consistency and to offset some of the disadvantages of the cascade training system. The dissemination session for those doctors working in obstetrics and pediatrics was aimed at both informing them and encouraging them to integrate the postnatal care package into their work and to facilitate referral and counter-referral practices. In addition, their inputs were incorporated in the development of the new guidelines. The session for RHM trainers focused on the description of the newly recommended postnatal care guidelines, the importance of incorporating messages to increase demand for the services into the tasks of the RHM, and a discussion on the potential role of the RHM in early postnatal coverage.

As part of the PNC training curriculum, the staff participated in exercises whose topics included on-site preparation and the organizational aspects required for the implementation of the newly recommended postnatal care guidelines.

Sharing of information by trained staff occurred in most of the sites to increase the numbers of providers delivering postnatal care. Knowledge and skills of the staff were evaluated during the supervision visits.

\footnotetext{
${ }^{4}$ Rural health motivators are based in the community and provide health messages and care.

${ }^{5}$ BASICS staff included one local and two regional (South African) facilitators receiving technical support from headquarters. They were responsible for the trainings and supervisory visits, accompanied only at the beginning by a headquarters technical advisor, who continued to provide support throughout the whole implementation period.
} 
In addition it was observed that staff in some of the facilities made extra job aids based on the materials provided by BASICS during the training.

\section{Content and method}

Due to the short duration of the intervention, the focus of the capacity building or training content emphasized the early postnatal period and the components of essential newborn care (Narayanan et al. 2004a) as the newest and most neglected areas. However other important elements of service delivery were included. These were selected aspects of antenatal care, labor and delivery, family planning, PMTCT, and HIV and AIDS care and treatment. The training therefore focused on:

a) Implementation of appropriately timed quality care during stay in the postnatal ward just before discharge, and at follow-up postnatal visits for the mother and the baby in the first week, preferably within the first three days, and in the sixth week, and their integration with PMTCT services.

b) Promotion of the importance of early postnatal visits during antenatal clinics and labor and delivery periods and integration with PMTCT services.

c) Facilitation of organizational changes to promote effective provision of care in the postnatal clinic (Maternal and Child Health or Public Health Unit).

d) Supervision to improve and maintain quality of services rendered.

e) Reinforcement of selected gaps in the continuum of care identified in the baseline assessment.

The training included a description of the intervention and justification, antenatal care, labor and delivery (emphasizing gaps encountered in the baseline evaluation), and content of the packages of care for the different postnatal care consultations, especially care of the low birth weight baby. Other elements of the intervention included site preparation and required organizational changes, supervision, and monitoring and evaluation. All aspects were linked to PMTCT and HIV and AIDS services. Due to time limitations and to the fact that by $\mathrm{MOH}$ mandate, treatment of postnatal complications in the mother and the baby is done by physicians in Swaziland, the training focused on identification of danger signs by the midwives and nurses and immediate notification to the physician (or referral from the clinics to the hospitals) for treatment.

The content was delivered as short lectures and discussions, group work (gap analysis exercises), demonstrations, and role play. Every morning there was an opportunity to reflect on learning from the day before or to discuss related issues. Every afternoon ended with the completion of a feedback form that requested information on key areas learned, related concerns, and suggestions for successful implementation.

A total of 132 health providers were either trained or oriented in the new postnatal package. In addition to those providers from project pilot sites, the MOHSW invited health providers from non-intervention sites to participate in the training. The additional providers trained were from Hlathikhulu Hospital and PHU providers from peripheral health facilities (nine participants), a nurse from the correctional system, and a nurse from the NGO Family Life Association of Swaziland (FLAS - an IPPF affiliate) providing sexual and reproductive health services including PMTCT. 


\section{Monitoring of training and supervision}

Postnatal services began in October 2006 in most sites; promotion of early postnatal visits was carried out at the antenatal clinics and at the pre-discharge assessments after delivery in the postnatal wards in the hospitals. By that time, the health facilities had adapted the existing physical space in the PHU or MCH and maternity ward and had made the organizational changes for the provision of the services.

Knowledge and skills of staff were evaluated during the supervision visits. From October 2006 to June 2007, monthly supervisory visits were carried out by members of the national core supervisory team and BASICS. The health providers were evaluated for their competence using pre-defined checklists of key tasks such as implementation of the pre-discharge package, counseling for infant feeding, and content of the postnatal consultations. A few short interviews with postpartum women were carried out at specific points of care to evaluate the key actions performed by the provider. Discussions with pregnant women leaving the ANC showed that the providers gave information on birth preparedness, danger signs in the newborn and necessary actions, and advice on the importance of the revised postnatal visits.

Relevant data from the clinics and hospital registers were also collected. Postnatal registers were designed and printed before the intervention and were oriented towards PMTCT data but lacked some relevant information for the mother and baby. However, there was no opportunity to recommend changes or additions at this stage. Nevertheless the hospitals were able to adapt the postnatal registers (by making additional columns) for the pre-discharge consultation and the early postnatal consultation which took place within 3-7 days. The information was recorded by site staff and collected by the supervisors during their visits. Since there are no medical records for follow up in health facilities, the only place to record the details of the post-natal consultation was on the maternal and child health card. BASICS was able to give inputs for a new version of the health cards that will include all the relevant information for the mother and the baby covered in the postnatal visits.

Some deficiencies were noted, mostly in the quality of the counseling, and were addressed during the supervision visits. The supervisory visits also included strengthening specific technical areas as required and holding meetings to discuss gaps and solutions. It was consistently observed that there was a lot of misinformation among providers, mothers, and families regarding infant feeding options for an HIVpositive mother. MOHSW requested BASICS to carry out two supervision visits to Hlathikhulu Hospital and PHU. Although a non-intervention site, the trained staff at this hospital had started to provide postnatal services according to the new proposed guidelines.

During the supervision period, BASICS participated in meetings with the MOHSW and facility supervisors to assist in processes regarding infrastructure, equipment and supplies, and staffing (including rotation of trained staff) to make the services efficient and effective. One key example was a meeting with the Deputy Director of Nursing for the MOH held in January 2007, with the participation of the Nursing Managers from the four regions of the Country, representatives from the core group of trainers, The Sexual and Reproductive Health Unit (SRHU) representatives, and BASICS. Issues related to shortage and rotation of staff, lack of equipment and supplies, sustainability of the strategy, and linkages with the community were presented and discussed. The response was very positive, and one of the immediate achievements of the meeting was an agreement to review the deployment of skilled staff and staff rotation activities. Many nurses were being moved to different wards and units every one to three months in the hospitals. This meant a potential increase in training costs in order to train everyone in the whole hospital in case they were transferred to the maternity or public health unit, or a loss of recently acquired skills and therefore a waste of resources. 


\section{Results of Supervision Activities}

Providers' knowledge on postnatal care was evaluated using a 20-question multiple choice questionnaire as part of pre- and post-tests during the training sessions. The results showed an increase in knowledge in key areas such as essential newborn care and danger signs for mother and baby. Figure 1 shows the average improvement in provider knowledge after the training for all sessions. The average increase was 16 percent. Participants expressed satisfaction with the content, methods, and facilitators, and commented that their expectations were met by the training.

Figure 1 Pre- and post-test scores for health providers during training in postnatal care (65 participants)

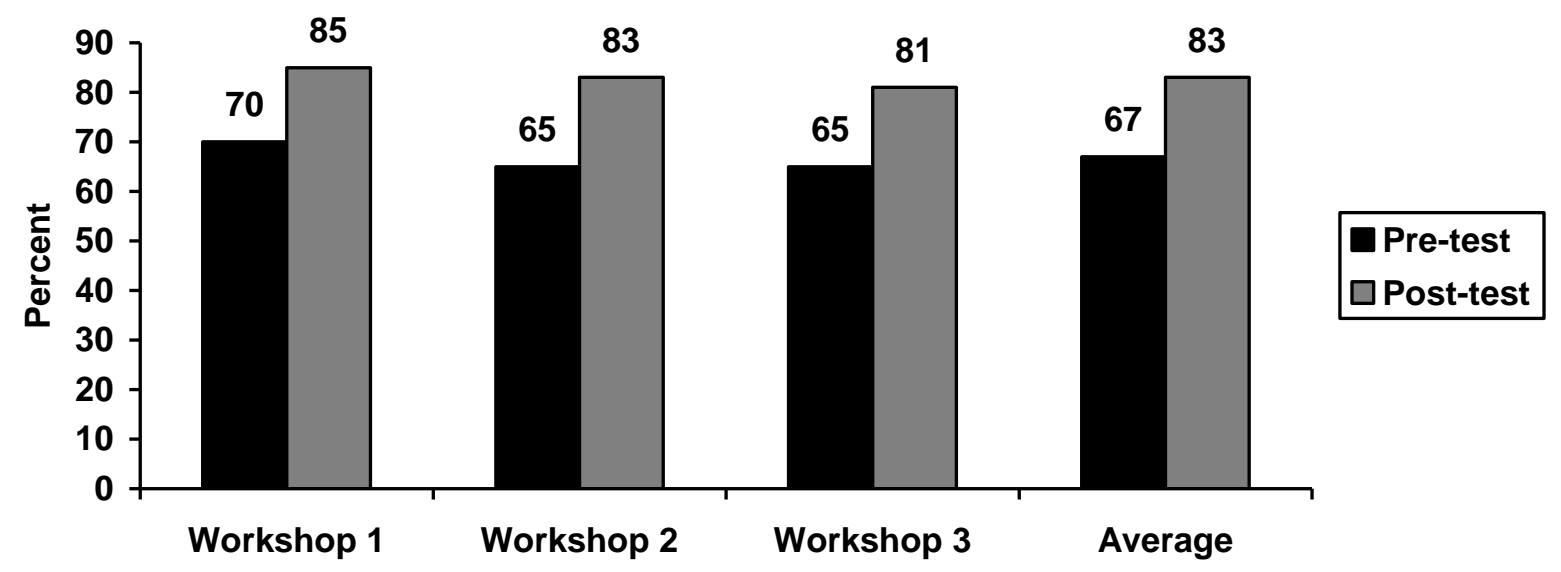

\section{Observations of provider-client interactions during postnatal consultations}

During the site visits, supervisors observed that the health providers showed consistently good performance during the various postnatal consultations, as shown in Figure 2. In addition, sharing of information by trained staff occurred in most sites, which increased the number of providers delivering improved postnatal care. Some facility staff made extra technical job aids based on the materials provided by BASICS during the training. These supervisory activities evaluated and strengthened the providers' competence and skills and not just knowledge. 
Figure 2 Mean percent of actions performed correctly during supervisory visits (with confidence intervals at $90 \%$ confidence level)

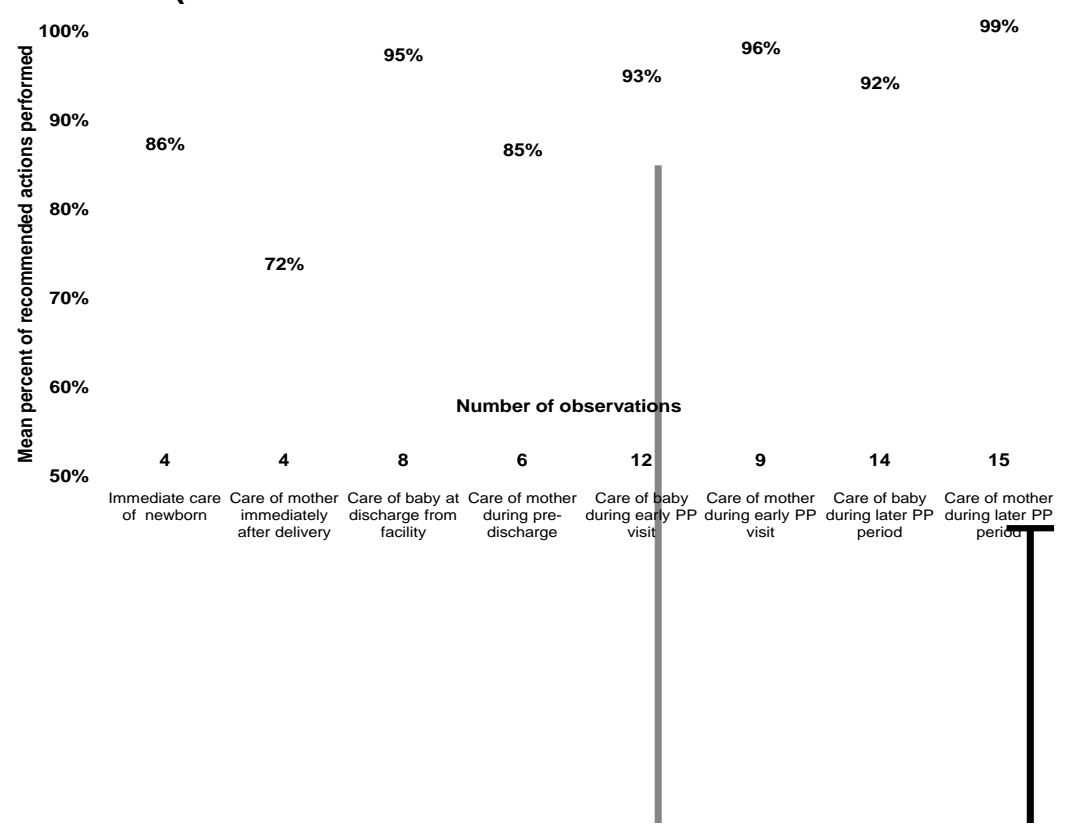

\section{Utilization of services}

During supervision, data were collected from the postnatal registers to document utilization of the postnatal services. Visits within three days increased 20-fold, visits between 4-7 days increased six-fold, and visits within 2-6 weeks after delivery increased four-fold, indicating increased repeat visits (see Figure 3). Anecdotally, postpartum women mentioned to providers that the new services brought an improvement in the quality of postnatal care and they greatly appreciated it.

Figure 3 Combined utilization of postnatal services at eight reporting program facilities

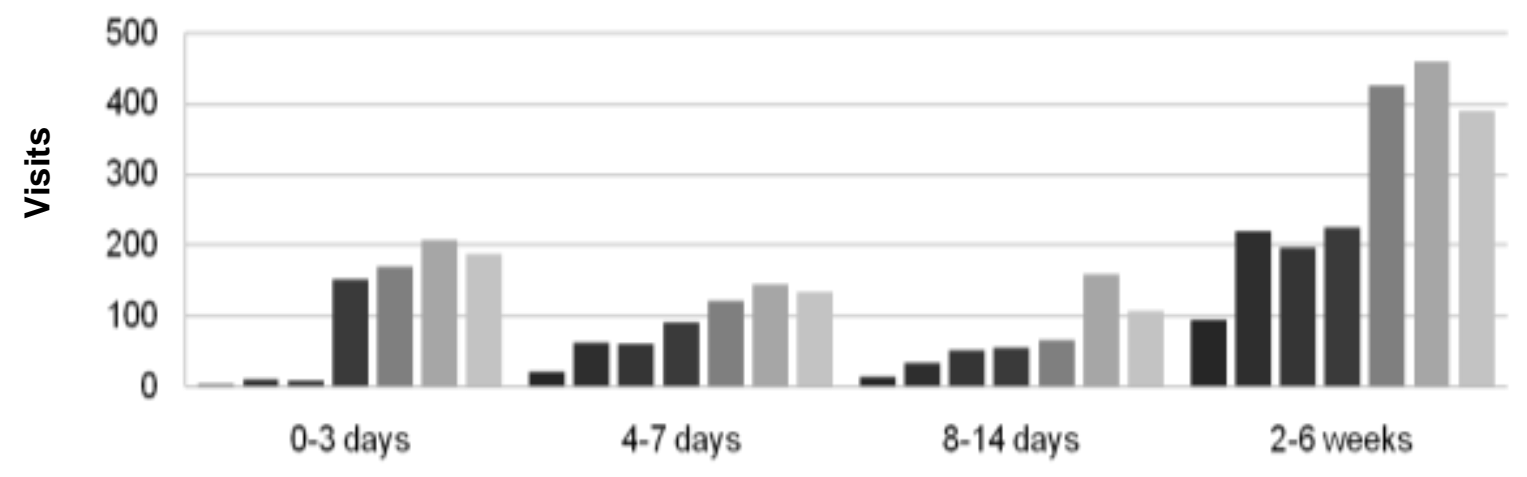

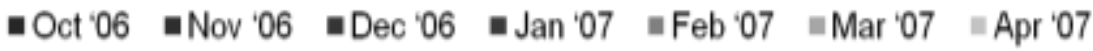




\section{Challenges during implementation}

One of the main challenges in the implementation of the intervention was the short timeframe for the activities. Unexpected delays took place prior to starting the training of the core group of trainers pending consensus on training content among partners. The additional programmed trainings were cancelled or dates were changed at short notice due to conflicting activities requiring the same trainees, with subsequent low attendance. Not all the health providers from the intervention sites were included in the training yet others were brought in from non-intervention sites.

Challenges for appropriate documentation included the existing MOHSW register for postnatal care, which is incomplete and does not provide enough information on essential care in the postnatal period. Plans were in place to update the register but this has yet to take place. Currently the postnatal register is strongly biased toward PMTCT care. This should be updated with input from experts with experience in maternal and newborn health (MNH) as well as PMTCT. This of course includes the nurse/midwives who are expected to complete the registers.

Although staff rotation was reduced somewhat during the intervention period, it is not known whether this will be sustained in the future. The shortage and rotation of staff (every month in some facilities) limits sustainability of the activities, especially in maternity wards.

Another challenge was convincing the health care providers to change the way they worked to be more efficient as well as to provide a comprehensive package of postnatal care. Many units assigned specific tasks to different nurses (for example, one nurse provided immunizations, one nurse did the physical examination, and yet another offered counseling on PMTCT, etc.) which made the client feel like she was on a conveyor belt. The ideal scenario is for one nurse to provide all care to the pregnant or postpartum woman and her infant in one room (which proved to be effective and efficient during the intervention).

Moreover there has to be full commitment from health managers to support the necessary changes to take place and to become institutionalized. In some instances during the early stages of the intervention, apparent lack of enthusiasm and commitment resulted in delays in implementation on the ground.

The staff complained time and again of a lack of equipment as a barrier to initiate the new postnatal package appropriately. Although there is a system in place to procure equipment, it is perceived as an extremely lengthy procedure and health providers do not believe the items requested will ever show up. Therefore providers rarely bothered to even put in a formal request. At the same time, the equipment required to provide postnatal care is minimal and feasible to obtain in-country.

\section{Sociodemographic Characteristics of Respondents}

The two main groups of respondents were the providers working in the maternity and public health units in the selected sites, and the postpartum women accessing the care in those sites. Their sociodemographic characteristics are described below. 


\section{Health providers}

The majority of the health providers were female (51/54 at baseline and 42/45 at endline) and "double qualified" (registered) nurse/midwives (59 percent at baseline and 87 percent at endline). The number of years worked at the facilities ranged from one year to 24 years; most had worked at their facility between one and three years.

\section{Postpartum women}

Table 2 outlines the demographic information of postpartum women (by HIV status) interviewed at the postnatal clinic at baseline and endline. The comparisons are between HIV-positive postpartum women before and after the intervention and between HIV-negative postpartum women before and after the intervention. Generally the demographic data is similar between the postpartum women interviewed at baseline and endline and by HIV status. However, significantly more HIV-positive postpartum women were cohabiting between the two surveys and more HIV-negative postpartum women had a higher education at endline.

Table 2 Percent distribution of postpartum women interviewed attending postnatal care at the time of the survey, by demographic characteristics and HIV

\begin{tabular}{|c|c|c|c|c|}
\hline & \multicolumn{2}{|c|}{$\begin{array}{c}\text { HIV-positive } \\
\text { postnatal mothers }\end{array}$} & \multicolumn{2}{|c|}{$\begin{array}{c}\text { HIV-negative } \\
\text { postnatal mothers }\end{array}$} \\
\hline & $\begin{array}{c}\text { Baseline } \\
(n=114) \\
\%\end{array}$ & $\begin{array}{c}\text { Endline } \\
(\mathrm{n}=136) \\
\%\end{array}$ & $\begin{array}{c}\text { Baseline } \\
\text { (n= 162) } \\
\%\end{array}$ & $\begin{array}{c}\text { Endline } \\
\text { (n= 191) } \\
\%\end{array}$ \\
\hline \multicolumn{5}{|l|}{ Age } \\
\hline Age $15-19$ years & 16 & 10 & 21 & 21 \\
\hline Age 20-24 years & 32 & 35 & 37 & 36 \\
\hline Age 25-29 years & 32 & 33 & 21 & 24 \\
\hline Age 30 years and older & 20 & 23 & 21 & 19 \\
\hline \multicolumn{5}{|l|}{ Marital status } \\
\hline Married & 39 & 43 & 46 & 51 \\
\hline Cohabiting & 22 & $13^{*}$ & 17 & 11 \\
\hline Single/other & 41 & 44 & 37 & 38 \\
\hline \multicolumn{5}{|l|}{ Education } \\
\hline Primary or lower & 39 & 30 & 37 & $27^{*}$ \\
\hline Incomplete secondary & 46 & 49 & 36 & 36 \\
\hline Completed secondary or above & 15 & 21 & 27 & $38^{*}$ \\
\hline \multicolumn{5}{|l|}{ Other health indicators } \\
\hline Parity (average child per mother) & 2.59 & 2.59 & 2.45 & 2.32 \\
\hline Child ever died & 10 & 10 & 10 & 7 \\
\hline Infant current birth age ( $<6$ weeks) & 21 & $32^{*}$ & 12 & $35^{\star *}$ \\
\hline
\end{tabular}

${ }^{*} p<0.05 ;{ }^{* *} p<0.01$ 


\section{Key Findings}

The pre-intervention system did not encourage postnatal care, as it was only recommended and available for postpartum women six weeks after giving birth and again only if a woman actually sought family planning services and the baby required immunizations. In addition, the existing antenatal care structure was a poor model for postnatal care, as postpartum women were expected to have multiple contacts of inadequate quality with health providers, which resulted in long hours spent at the facility. Observations of client-provider interactions prior to the intervention showed that each pregnant woman spent an average of four hours at the facility for her first ANC visit $(n=48)$ without necessarily receiving good quality care.

\section{Facility Preparedness to Offer the New Postnatal Package}

Prior to the intervention, the study sought to assess the availability and functioning of the basic infrastructure necessary for offering quality postnatal services even though the MOHSW could not improve some items (such as number of consulting rooms or equipment) within the period of the intervention. An index of clinic preparedness was constructed using four indicators:

- Availability of services (Score range: 0-13) included weighing the client, taking blood pressure, health education sessions, counseling for HIV, birth preparedness and family planning, blood tests (anemia, syphilis, and HIV), urine testing, tetanus toxoid vaccination, PMTCT, treatment of STIs.

- Availability of essential equipment (Score range: 0-10) incorporated essential items such as blood pressure machine, stethoscope, foetoscope, scales (adult and infant), tape measure, thermometer, speculum, examination couch, and spotlights.

- Availability of essential drugs and vaccinations (Score range: 0-21) included the expected range of micronutrient supplements, antibiotics, (such as cotrimoxazole, gentamicin, and amoxicillin in tablet, injection, and syrup forms) vaccines (Polio, BCG, DTP/HBV, Measles, TT, and DT) and ARV tablets and syrups (Nevirapine, AZT, ZDV, and Combivir).

- Availability of in-service staff trainings within past year (Score range 0-23) ranged from updates in different aspects of PMTCT, HIV counseling, and support to comprehensive antenatal care, screening and management of TB and STIs, management of labor, newborn care (low birth weight, sick

newborn), infant feeding, integrated management of childhood illnesses (IMCI), and postnatal care.

Data were drawn from the facility assessment tool and mean scores were computed for each indicator and then aggregated across all indicators to give the composite score for clinic preparedness. Overall the pilot facilities had the capacity to provide postnatal care specifically in the public health units. Essential drugs and supplies were the least likely to be available (see Table 3). 


\begin{tabular}{|c|c|c|c|}
\hline & $\begin{array}{c}\text { Maternity } \\
\text { and PHU } \\
\text { average score } \\
(n=7)\end{array}$ & $\begin{array}{c}\text { Maternity } \\
\text { unit only } \\
\text { average score } \\
(n=3)\end{array}$ & $\begin{array}{l}\text { Public health } \\
\text { unit only } \\
\text { average score } \\
(n=4)\end{array}$ \\
\hline \multicolumn{4}{|l|}{ Availability of } \\
\hline Services offered (0-13) & 10.14 & 7.33 & 12.25 \\
\hline Equipment available $(0-10)$ & 9.14 & 8.67 & 9.50 \\
\hline Drugs/vaccinations (0-21) & 14.29 & 11.33 & 16.50 \\
\hline In-service staff training in past $(0-23)$ & 19.14 & 18.67 & 19.50 \\
\hline Total score (0-67) & 52.71 & 46.00 & 57.75 \\
\hline
\end{tabular}

\section{Provider Knowledge of Maternal and Newborn Health}

Providers' awareness of $\mathrm{MCH}$, including the continuum of care from pregnancy through the postnatal period, was initially assessed through their exposure to $\mathrm{MCH}$ during in-service training. A number of topics were covered within the year preceding each study. However, even though a number of health providers received some type of updates, results suggest that training alone is not enough and real improvement is noted when training and supervision go hand in hand. Less than one-third of the providers did not receive updates on ANC, which has repercussions in the continuum of care for a pregnant woman. There was an increase in the proportion of providers who said they had received training in: postnatal care (from 37 percent to 66 percent); in basic newborn care (from 40 percent to 57 percent); and care of the sick newborn (from 33 percent to 49 percent). More providers said they had been trained in PMTCT (from 78 percent to 86 percent) and counseling for prevention of HIV (from 70 percent to 80 percent). However, training in family planning increased only slightly (from 28 percent to 37 percent) and counseling for social support for HIV-positive clients stayed the same at 57 percent.

\section{Health Provider Knowledge of Pre-discharge Care and Maternal and Newborn Essential Care}

\section{Health providers' knowledge on pre-discharge care for infant}

Results from health provider interviews demonstrated significant improvements in their knowledge of counseling and support for care of the infant after birth before discharge from the hospital. There were significant increases among health providers who said they would observe proper feeding before discharge, from 28 percent to 80 percent $(\mathrm{p}<0.01)$. In addition, a significant increase was noted among health providers who said they would observe proper attachment and positioning of the breastfeeding baby, from 22 percent to 51 percent $(\mathrm{p}<0.01)$. 


\section{Essential newborn care}

There were a number of improvements in providers' knowledge on some aspects of essential newborn care as a result of the intervention. Knowledge of the steps to maintain the baby's temperature at birth (dry baby immediately, wrap baby in dry cloth and cover head) increased significantly (see Figure 4).

\section{Figure 4 Percent distribution of providers' knowledge of baby's temperature maintenance at birth}

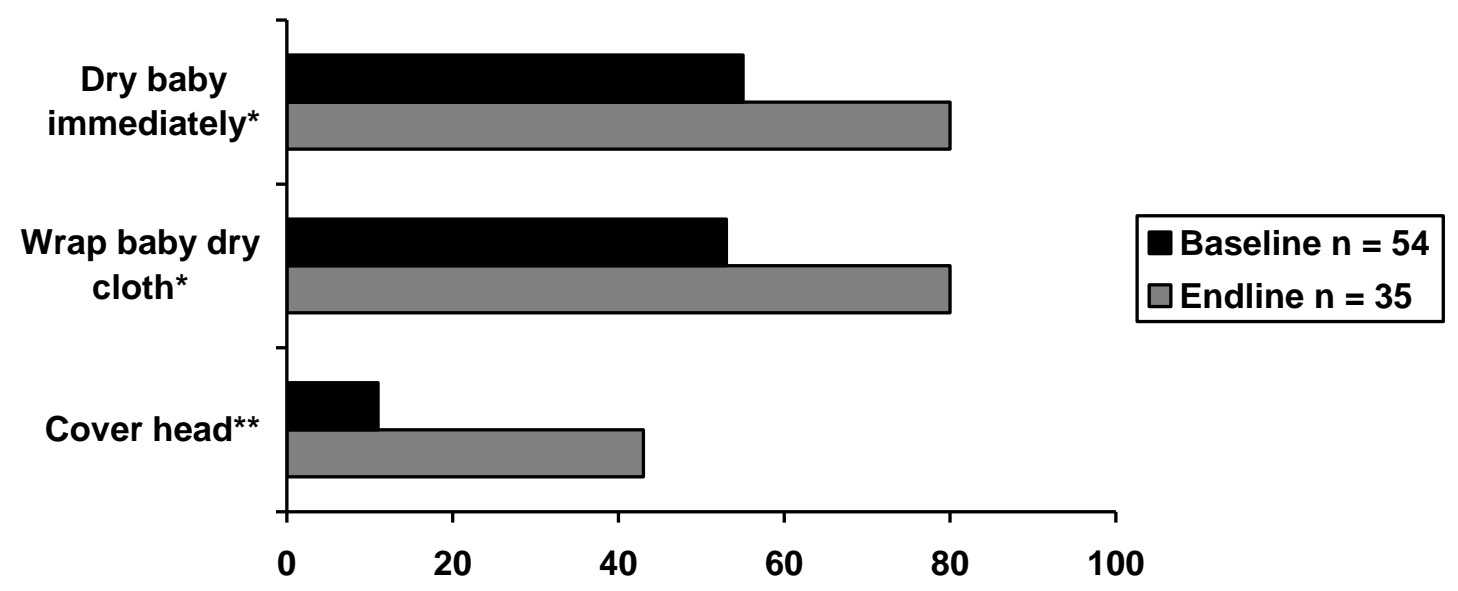

${ }^{*} p<0.05 ;{ }^{* *} p<0.01$

In addition more providers said they would advise postpartum women on appropriate infant bathing (delay first bath and use warm water). This increased from 22 percent at baseline to 49 percent at endline $(\mathrm{p}<0.01)$. Advice on infant temperature control increased significantly from 7 percent to 51 percent $(\mathrm{p}<$ 0.01). There were, however, no significant changes in advice on infant cord or eye care post-intervention. Although there was a significant overall increase, only about half of the providers were able to recall all aspects of care required; this increased from 1.46 indicators (out of a total of 6) per provider at baseline to 3.17 indicators per provider at endline.

\section{Health provider knowledge of maternal and newborn complications}

Health provider knowledge of maternal and newborn complications in the postnatal period was measured using a scale aggregating scores from indicators of the main causes of maternal and neonatal morbidity and mortality. The scores were generated from the provider knowledge questionnaire and an average score computed for each component (see below). Knowledge of maternal complications included the signs of and appropriate actions for postnatal hemorrhage (PPH) and puerperal infection. Knowledge of newborn complications included indicators for asphyxia, infection, and low birth weight. 


\section{Provider knowledge of maternal complications in postnatal period}

Providers were asked about detecting and managing maternal complications that are major causes of maternal death within the postnatal period. Knowledge scores on essential components were computed. Provider knowledge was tested on how to detect PPH, which includes five essential signs: un-contracted uterus, signs of shock, amount of external bleeding, retained placenta, and full bladder. Knowledge on how to manage PPH includes four essential "actions" that must be recalled for the PPH action score. These are: massage the fundus, empty the woman's bladder, give IV oxytocin, and start IV fluids. There were no significant improvements in provider knowledge in recognition and management of postnatal hemorrhage post-intervention.

Signs of puerperal sepsis include: high pulse, high fever, systolic blood pressure less than 90mmHg, subinvoluted tender uterus, foul-smelling lochia, and tender abdomen. Sepsis action includes: start intravenous fluids, give intravenous antibiotics, administer analgesics/antipyretics, palpate abdomen, and examine lochia, perineum, and breasts. There were notable increases in knowledge of signs for postnatal infection, with a mean score increase from 2.07 to 3.77 out of a total of seven $(p<0.01)$. Increases in knowledge of actions to take for postnatal infection in the mother also increased from a mean score of 2.00 to 2.74 ( $p<0.01$ ). Overall there was a significant increase in provider knowledge on a range of danger signs in the postnatal period, from 10.07 to 13.77 out of $27(\mathrm{p}<0.01)$.

\section{Provider knowledge of newborn complications}

Table 4 outlines overall increase in knowledge of aspects of newborn care. It indicates that there were some significant improvements in provider knowledge on complications in the newborn, specifically in the areas of signs of asphyxia, actions required if newborn fails to breathe at birth, and danger signs in the newborn. However, there were no changes in knowledge actions for danger signs suggesting sepsis and care of the low birth weight infant.

Table 4 Health provider knowledge of newborn care

\begin{tabular}{lcc}
\hline & $\begin{array}{c}\text { Baseline } \\
(\mathbf{n}=\mathbf{5 4}) \\
\text { Average score }\end{array}$ & $\begin{array}{c}\text { Endline } \\
(\mathbf{n}=\mathbf{3 5}) \\
\text { Average score }\end{array}$ \\
\hline Newborn health components & & \\
$\quad$ Signs of asphyxia (range 0-5)** & 2.31 & 3.17 \\
$\quad$ Actions for failed breathing (range 0-7)* & 2.52 & 3.34 \\
Steps to start ventilation (range 0-7) & 2.31 & 3.03 \\
Danger signs (range 0-5)** & 1.78 & 3.03 \\
Actions for danger signs (range 0-6) & 2.00 & 2.40 \\
$\quad$ Care of low birth weight infant (range 0-6) & 2.57 & 2.94 \\
Total index for newborn health (range 0-36) & 13.50 & 17.91 \\
\hline
\end{tabular}

Note: Taken from data on provider interview.

${ }^{*} \mathrm{p}<0.05 ;{ }^{* *} \mathrm{p}<0.01$ 
There were some dramatic improvements on provider's knowledge on specific danger signs to look out for in the newborn (see Figure 5).

Figure 5 Percent distribution of providers' knowledge of danger signs in the newborn (by interview)

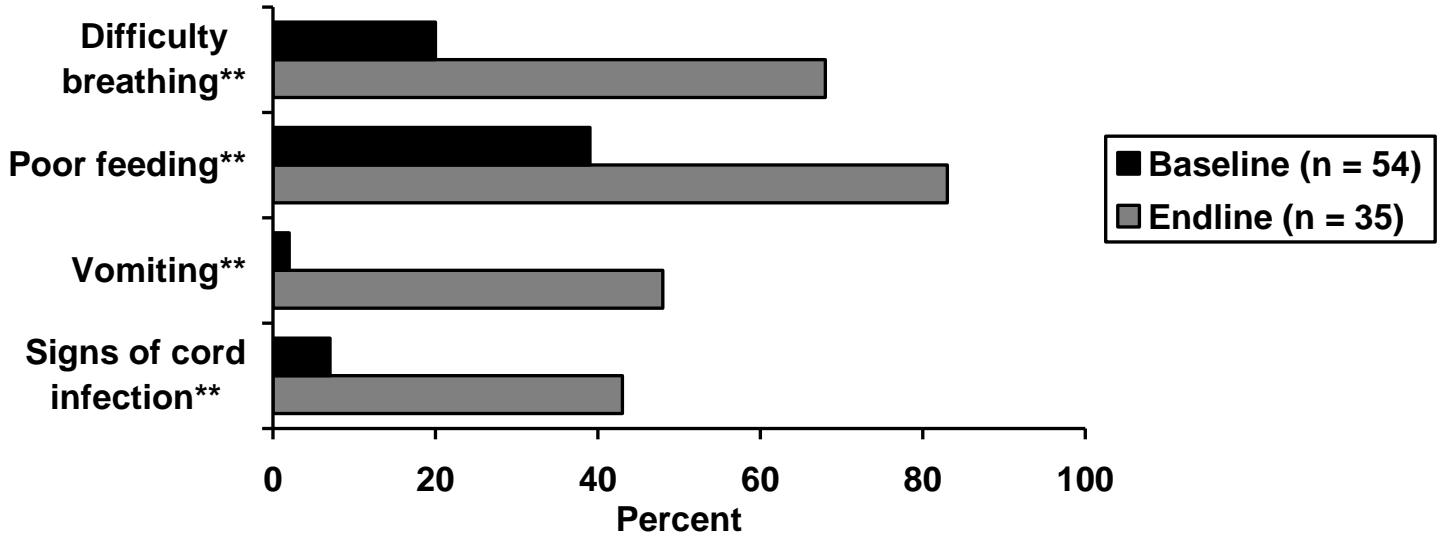

${ }^{* *} \mathrm{p}<0.01$

\section{Quality of Care Observed Through Client-provider Interactions}

\section{Information given to pregnant women in the antenatal period on elements of care related to labor, delivery, and the postnatal period}

To assess the quality of care across the continuum from pregnancy, immediately after birth, and into the postnatal period, client-provider interactions were observed in both the antenatal and postnatal clinic. Interactions between pregnant women and health providers were observed in the antenatal clinic for pregnant women in their first visit to the ANC and for those who were in their final month of pregnancy (from 36 weeks and above). Women were observed at this point to understand whether health providers were giving sufficient information to prepare pregnant women for labor, childbirth, and the postnatal period.

\section{Information on signs of onset of labor and counseling on post-delivery care}

There was improvement in pregnant women being advised of signs of onset of labor (intermittent low abdominal pain, mucoid blood stained vaginal discharge, and watery vaginal discharge or sudden gush of water) from 40 percent to 81 percent $(\mathrm{p}=0.066)$. However, there were no changes in the number of observed interactions where providers advised or counseled pregnant women on infant feeding (such as management of breast problems and types of feeding), post-delivery care, personal and infant hygiene, or family planning after childbirth during the later ANC consultations. It is important to highlight that advice on infant feeding in the first antenatal visit increased significantly, from 35 percent to 63 percent $(p<0.05)$. While it is important at this time for women to start thinking of options, the messages must also be reinforced later in the pregnancy. 
Healthcare providers in ANC are expected to counsel pregnant women on a range of key danger signs that cause concern during pregnancy ( 9 danger signs), labor and childbirth ( 9 danger signs), after delivery (6 danger signs), and in the newborn (9 danger signs). These danger signs are similar to those outlined in the next section. Significant improvements were observed; specifically in providers counseling pregnant women about the danger signs during pregnancy, labor, and childbirth. However, only minimal improvements were noted for counseling on danger signs in the newborn (see Table 5).

Table 5 Observed provider counseling in ANC on danger signs during pregnancy, childbirth, post delivery, and in the newborn

\begin{tabular}{lcc}
\hline & $\begin{array}{c}\text { Baseline } \\
\text { Average score } \\
(\mathbf{n}=\mathbf{5 0})\end{array}$ & $\begin{array}{c}\text { Endline } \\
\text { Average score } \\
(\mathbf{n}=\mathbf{3 7})\end{array}$ \\
\hline Average number of danger signs mentioned to women in ANC & & \\
$\quad$ Danger signs during pregnancy (range 0-9)** & 0.72 & 2.41 \\
Danger signs during labor and childbirth (range 0-9) $)^{* *}$ & 0.22 & 1.32 \\
Danger signs post-delivery (range 0-6) & 0.08 & 0.35 \\
Danger signs in the newborn (range 0-9) & 0.00 & 0.30 \\
\hline
\end{tabular}

Note: Taken from data on pregnant women visiting ANC $\geq 36$ weeks gestation.

${ }^{* *} \mathrm{p}<0.01$

Birth planning and emergency preparedness

Significant increases were observed in providers advising pregnant women about birth planning and emergency preparedness during the ANC for pregnant women during their $8^{\text {th }}$ month of gestation. Pregnant women were observed being asked where they were going to give birth. This increased from 4 percent at baseline to 35 percent at endline, and similar significant increases were noted for pregnant women who were advised to give birth in a facility (from 6 percent to 35 percent; $p<0.001$ ); advised about supplies to have at home prior to the delivery (from 2 percent to 14 percent; $p<0.05$ ); and encouraged to identify a specific facility to give birth (from 2 percent to 16 percent; $p<0.05$ ).

\section{Advice given during ANC consultation on when pregnant women should return for postnatal care}

There was a highly significant increase in the percentage of pregnant women (during the eighth month visit) who were observed being advised during the ANC to come for a one week check up after childbirth (from 2 percent to 32 percent; $p<0.001$ ). Moreover, there was an overall increase in advice to attend the postnatal clinic (which includes visits before three days and at one week) between delivery and six weeks (from 12 percent to 57 percent; $p<0.001$ ). These data are consistent with that obtained from the postpartum women exit interviews where there was a significant increase (from 1 percent to 37 percent; $p$ $<0.001$ ) among the postpartum women who could recall that the health care provider in the antenatal clinic advised them to come back to the $\mathrm{MCH} / \mathrm{PHU}$ one week after they had given birth. 
Pregnant women were more likely to be observed being advised to bring their newborn infants for checkups and/or immunizations. Advice by health providers for pregnant women to bring the newborn for a one-week check up increased from 4 percent to 38 percent $(\mathrm{p}<0.001)$. The percentage of pregnant women observed being advised to bring their infants for immunization at six weeks increased from 4 percent to 19 percent $(\mathrm{p}<0.05)$ Overall there was a highly significant increase for all recommended follow up visits (from 22 percent to 81 percent; $\mathrm{p}<0.01$ ).

\section{The Postnatal Period}

The observations of the interactions between health providers and postpartum women looked at a range of maternal and newborn issues that are part of the postnatal package, both on the postnatal ward (endline only) and the postnatal clinic (baseline and endline).

\section{Immediate postnatal care after birth and pre-discharge}

The data collected at endline on the postnatal ward, both observations and client exit interviews, are discussed with regard to quality of care and follow up of services. Among the 28 interactions observed between the health providers and newly delivered postnatal mothers, a number of positive trends were demonstrated. Rapport between the health care provider and postnatal mother appeared to be good. In almost all of the sessions (93 percent), women were assured of privacy in 71 percent women were made to feel welcome, in 68 percent women were greeted, and 54 percent of consultations were assured of confidentiality. During the majority of the observations mothers were asked how they felt (96 percent) and encouraged to ask questions (68 percent). Moreover, in 68 percent of the sessions the health care provider responded immediately to maternal problems, and 64 percent responded to the newborn's problems.

The postnatal package of care requires health care providers to inquire about any possible danger signs of the mother and baby as well as to advise them on how to watch for these signs and seek care early if they are noticed. In the majority of interactions ( 86 percent), postpartum women were observed being asked about any bleeding since birth, the color (54 percent) and smell (68 percent) of lochia, the condition of the perineum (79 percent), signs of thrombosis (61 percent), and condition of breasts (46 percent). Similar results were noted in actual counseling of danger signs in the mother. Almost all postpartum women (93 percent) were given a general examination where 93 percent were observed being palpated and 96 percent had their breasts examined. Furthermore during the consultations postpartum women had their blood pressure ( 96 percent), temperature ( 89 percent), and their pulse ( 75 percent) measured.

All mothers were observed receiving advice on immunizations and during 96 percent of the observations newborns received Polio 0 and BCG in the ward. Providers spent time describing the danger signs in the newborn to the mother, for example, difficulty breathing (100 percent), fever (100 percent), hypothermia (57 percent), redness around umbilical stump (96 percent), not sucking (86 percent), convulsions (100 percent), and jaundice (57 percent).

In about half the sessions the health care provider advised postpartum women on essential newborn care including the need to monitor cord care (68 percent), temperature monitoring (57 percent), and general hygiene when handling the baby (50 percent). In 89 percent of the observations, newborns were examined. This included their weight and temperature recorded ( 75 percent), cord checked (96 percent), 
eyes examined ( 89 percent), and confirmation that meconium had passed ( 68 percent). Almost all postpartum women (93 percent) were counseled to return for the early postnatal consultation at the clinic and an appointment was given in 82 percent of cases.

\section{Care at the postnatal clinic}

The observations of client-provider interactions looked at a range of maternal and newborn issues that are part of the new postnatal package. An index of maternal health components was constructed using four indicators. Data were drawn from the client-provider observation tool, and mean scores were computed for each indicator and then aggregated across all indicators to give the composite score for maternal health.

Maternal health components:

These include average number of providers observed assessing, providing care, and counseling:

- Asking for presence of danger signs (Score range 0-10) that might have occurred since birth: bleeding; smell and color of lochia; condition of scars from episiotomy/caesarean section; fever, headaches, swelling of face, hands, or legs; thrombophlebitis; etc.

- Physical examinations conducted and care give (Score range 0-10): observe general appearance, weight, temperature, pulse, blood pressure, pallor, breasts, lymph nodes (for TB), uterine involution, and micronutrient supplements

- Tests conducted (Score range 0-2): HIV and Hemoglobin test

- Counseling on danger signs specific to the early postnatal period (Score range 0-3): excessive bleeding, foul smelling discharge, and broken episiotomy site.

An index of newborn health components was also constructed using four indicators, and mean scores computed for each indicator.

Newborn health components:

- Assessment of danger signs after birth (Score range 0-7): difficulty breathing, difficulty feeding (such as poor sucking or not sucking), jaundice, redness/ swelling around cord, fever/too cold, vomiting.

- Counseling on danger signs specific to the early postnatal period (Score range 0-6): difficulty breathing/feeding, jaundice, redness/ swelling around cord, fever/too cold.

- Infant feeding counseling (Score range 0-10): advise on infant feeding, request demonstration of mother breastfeeding infant, assess position and attachment during breastfeeding, encourage mother to discuss management of breastfeeding, and re-emphasize exclusive breastfeeding.

- Immunizations administered (Score range 0-3): Polio, BCG, DPT.

Table 6 shows a summary of the components outlined above that indicates the quality of care the mothers and newborns received in the postnatal clinic. Due to the change in the recommended timing of visits during the intervention, a significant proportion of postpartum women at endline visited the PNC clinic when their infants were younger than six weeks in comparison to baseline ( 58 percent versus 6 percent). 


\begin{tabular}{|c|c|c|}
\hline Quality of care index & $\begin{array}{c}\text { Baseline } \\
\text { Average score } \\
(n=50)\end{array}$ & $\begin{array}{c}\text { Endline } \\
\text { Average score } \\
(n=117)\end{array}$ \\
\hline \multicolumn{3}{|l|}{ Maternal health components } \\
\hline Asking about any danger signs $(0-10)^{\star *}$ & 0.22 & 3.23 \\
\hline Counseling on danger signs in early PN period $(0-3)^{\star *}$ & 0.10 & 1.47 \\
\hline Physical examinations conducted $(0-10)^{\star *}$ & 1.64 & 6.09 \\
\hline Tests conducted $(0-2)^{\star *}$ & 0.16 & 1.04 \\
\hline Total index for maternal health (range $0-25)^{* *}$ & 1.84 & 10.94 \\
\hline \multicolumn{3}{|l|}{ Newborn health components } \\
\hline Asking about any danger signs $(0-7)^{\star *}$ & 0.26 & 3.07 \\
\hline Counseling on possible danger signs $(0-6)^{\star *}$ & 0.32 & 3.33 \\
\hline Counseling on infant feeding $(0-6)^{\star *}$ & 0.28 & 2.20 \\
\hline Immunizations received $(0-3)^{\star *}$ & 1.68 & 1.19 \\
\hline Total quality of care index for newborn health $(0-22)^{\star *}$ & 2.90 & 10.79 \\
\hline
\end{tabular}

${ }^{* *} p<0.01$

All components of quality of care increased significantly over the study period. Although increases were substantial, average endline values were less than half of the maximum value attainable. For example, average maternal health index was 44 percent of maximum, and average newborn health was 49 percent of maximum.

The examination of mothers showed improvement in key areas, as seen in Figure 6. Examination of the newborn was not assessed at baseline. However, at endline 97 percent of providers examined the infant: weight ( 95 percent), measured temperature (46 percent), assessed cord ( 85 percent), and checked eyes (72 percent). Around two-thirds (67 percent) of providers were observed checking the newborn specifically for danger signs. 
Figure 6 Percentage of observed providers who performed specific actions during examination of mother in the postnatal consultation in the clinic

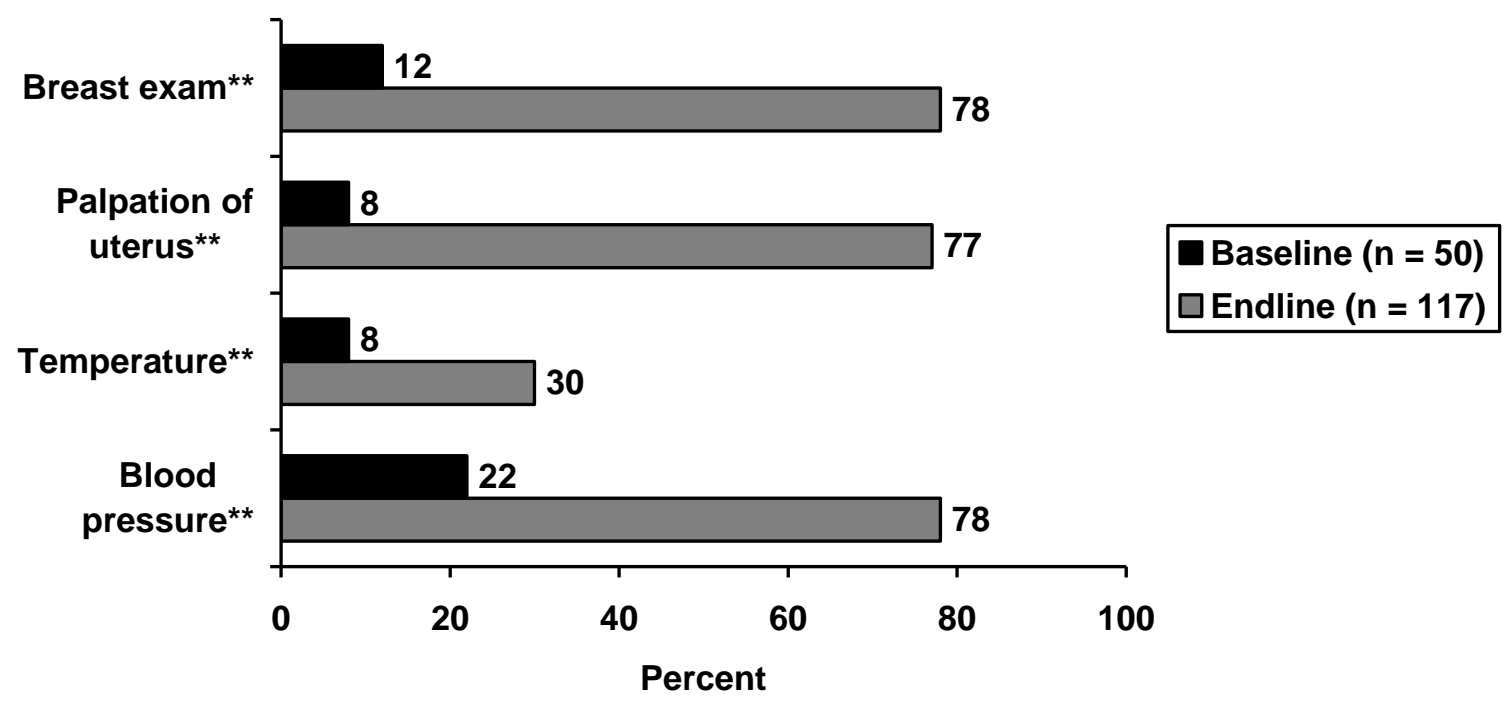

${ }^{* *} p<0.01$

An important area to highlight is the trend in postnatal quality of care for counseling on danger signs, as this was a targeted improvement area during the intervention. Figure 7 displays the detailed indicators for counseling on the specific component on maternal danger signs. These indicators for the postnatal mother (counseling for excessive bleeding, foul smelling vaginal discharge and broken perineal scar/tear) are in addition to simply asking about danger signs.

Figure 7 Percentage of observed providers who counseled on danger signs for mother during the postnatal consultation

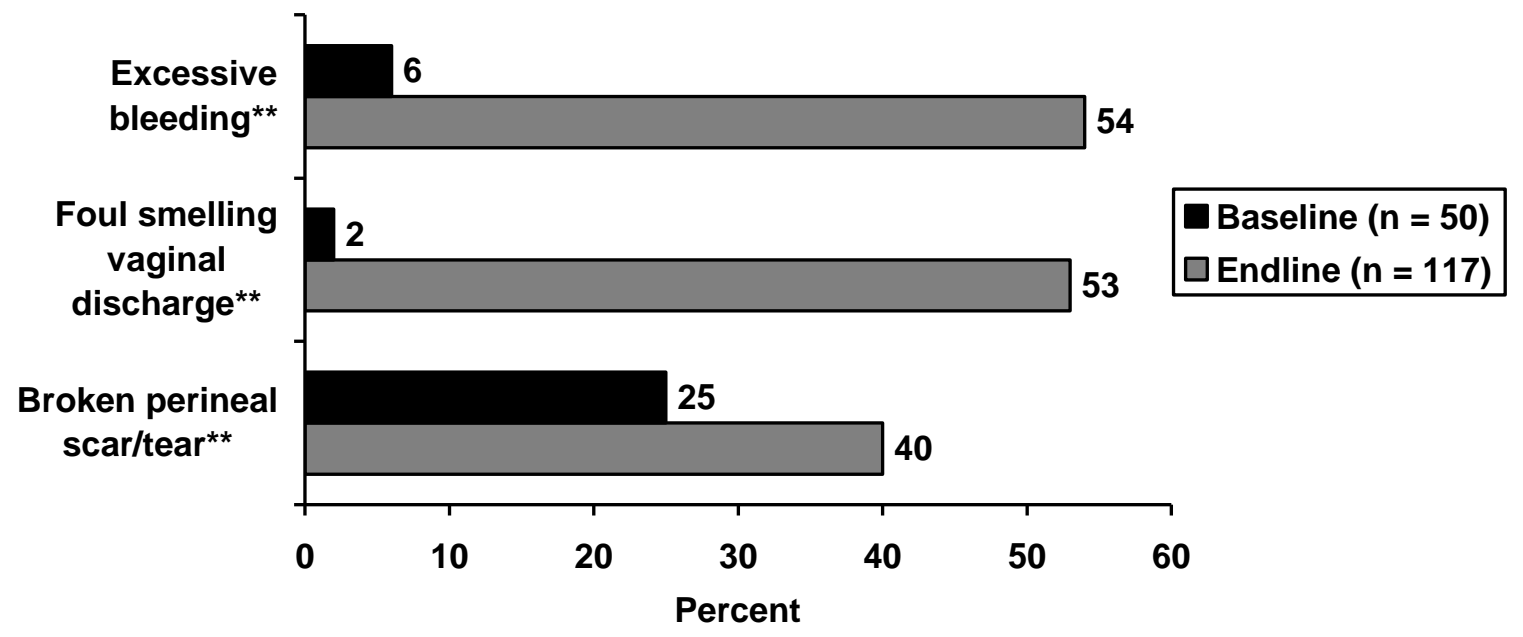

${ }^{* *} p<0.01$ 
There were also significant increases in the proportion of providers observed counseling for individual danger signs in the newborn (see Figure 8).

\section{Figure 8 Percent distribution of observed providers who counseled on danger signs for infant during the postnatal consultation}

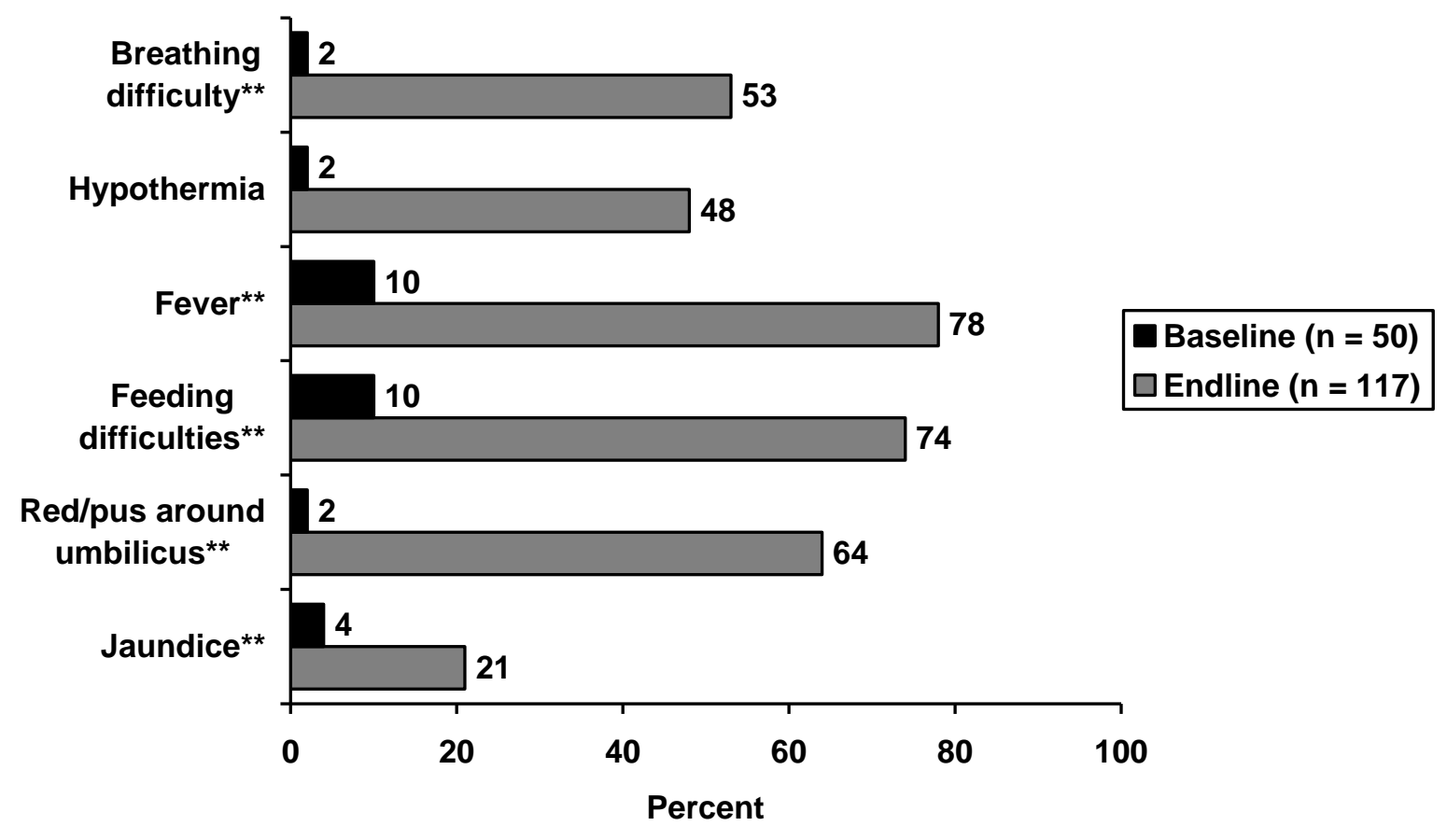

${ }^{* *} p<0.01$

Counseling on exclusive breastfeeding during the postnatal consultations improved dramatically from 18 percent to 79 percent. Provider performance regarding advice for other components of essential newborn care such as temperature maintenance (46 percent) and cord care (62 percent) was only measured at endline.

\section{Experience of Postpartum Women}

Among the postpartum women interviewed as they were leaving the postnatal clinic, there were more postpartum women with infants under six weeks old at endline. Earlier timing of the postnatal visits increased significantly from 21 percent to 32 percent $(\mathrm{p}<0.05)$ for HIV-positive postpartum women, and increased from 12 percent to 35 percent $(\mathrm{p}<0.01)$ among HIV-negative postpartum women. 


\section{Postpartum women's recall of being counseled by health provider on postnatal essential obstetric and newborn care}

Changes were found in postpartum women's recall of being counseled by health providers on some elements of basic care for themselves and their babies. While recall on general hygiene and care of breasts remained unchanged, counseling on issues such as getting plenty of rest (a reduction from 24 percent to 12 percent) and adding more nutritious foods (from 67 percent to 37 percent) decreased. For essential newborn care, postpartum women's knowledge on exclusive breastfeeding remained unchanged at 70 percent. One aspect that improved marginally was counseling on the correct way to check a baby's temperature (by touching tummy and compare temperature with all limbs; all should be warm), this increased from 1 percent to 9 percent. Knowledge in other aspects decreased, such as dry and clean cord care (from 62 percent to 44 percent).

\section{Postpartum women's recall of being counseled by health providers on danger signs of complications in mother and newborn}

Counseling on danger signs in the mother and newborn during the first few weeks after delivery was assessed by interviewing postpartum women exiting the postnatal clinic. There were significant increases between the baseline and endline surveys in the percentage of postpartum women who could recall that the health provider discussed with them that excessive bleeding and severe abdominal pain were serious problems (from 42 percent to 60 percent; $\mathrm{p}<0.001$, and from 11 percent to 20 percent; $\mathrm{p}<0.001$, respectively). Although the health providers were observed giving this information during the postnatal consultations, there were significant decreases among the postnatal mothers' recall of possible breast problems and importance of seeking care early for any foul smelling vaginal discharge. Indeed there were similar reductions noted in the recall of receiving advise about danger signs in the newborn (these include feeding difficulties, breathing difficulties, infected umbilicus, fever and hypothermia, abdominal distention, vomiting, and convulsions) with a significant overall reduction in the total index score from 0.77 to 0.58 (out of 8 ).

\section{Infant Feeding Practices}

\section{Feeding practices among HIV-positive and HIV-negative postpartum women}

Among postpartum women interviewed in the ward after delivering their baby, 87 percent said they were exclusively breastfeeding their baby (78 percent of HIV-positive mothers and 90 percent of HIV-negative mothers) and 22 percent said they were able to initiate feeding in the labor ward. The majority (75 percent) of mothers who were unable to feed in the labor ward said they were taken to the postnatal ward before starting breastfeeding. Nevertheless, half of the women were able to feed their newborns within one hour of birth. Over a third (37 percent) of postpartum women in the ward said that the health care providers reiterated exclusive breastfeeding to them. All recently delivered breastfeeding women $(n=84)$ on the postnatal ward were asked how long they expected to breastfeed their babies. Table 7 shows the different results between HIV-positive and HIV-negative women. Reasons given for specific time periods were: need to get back to work (17 percent), advised to stop at six months (33 percent), and "I fed my other children that way" (36 percent). 
Table 7 Anticipated time period for breastfeeding among postpartum women interviewed in the PN ward

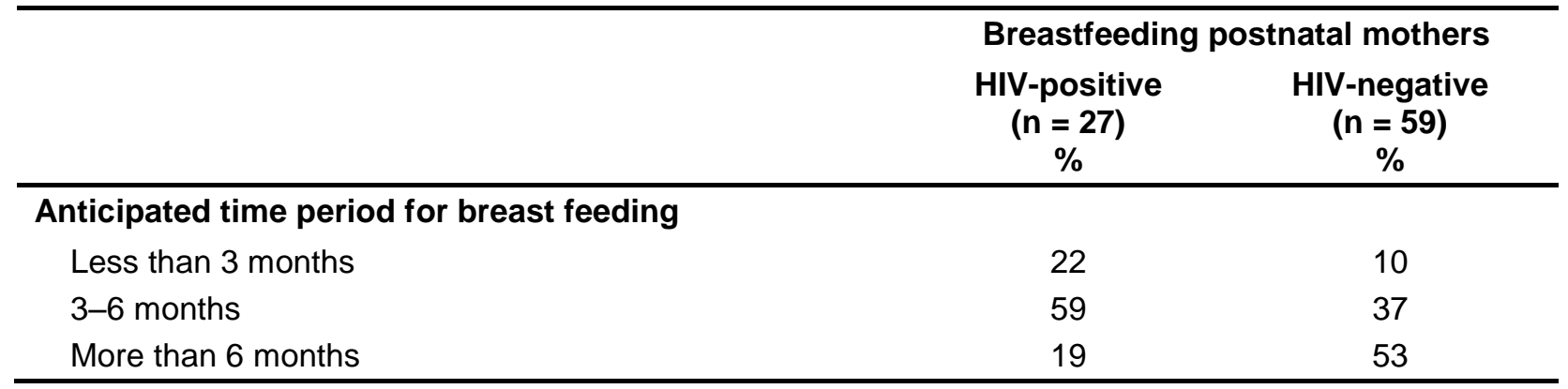

There were no significant changes in the proportion of postpartum women interviewed in the postnatal clinic who could recall receiving information on infant feeding in the antenatal clinic or maternity unit. Although there was no notable increase in breastfeeding among HIV-positive postnatal mothers, significantly more HIV-negative postpartum women were breastfeeding; and as a result fewer were using replacement feeds. The proportion of HIV-positive postpartum women who were mixed feeding also went down.

Around 86 percent of all breastfeeding postpartum women interviewed at the clinic said they were able to breastfeed their newborn in the labor ward, and significant increases were noted among those women who said they breastfed their newborns within one hour after birth (see Table 8).

\section{Table 8 Infant feeding behavior by HIV status of postpartum women interviewed at the PNC clinic}

\begin{tabular}{|c|c|c|c|c|}
\hline \multirow[t]{2}{*}{ Indicator } & \multicolumn{2}{|c|}{ HIV-positive mother } & \multicolumn{2}{|c|}{ HIV-negative mother } \\
\hline & $\begin{array}{c}\text { Baseline } \\
(n=114) \\
\%\end{array}$ & $\begin{array}{c}\text { Endline } \\
(n=136) \\
\%\end{array}$ & $\begin{array}{c}\text { Baseline } \\
(n=162) \\
\%\end{array}$ & $\begin{array}{c}\text { Endline } \\
(\mathrm{n}=191) \\
\%\end{array}$ \\
\hline \multicolumn{5}{|l|}{ Counseling recall } \\
\hline Informed in ANC visits about feeding & 82 & 79 & 68 & 70 \\
\hline Informed in labor ward about feeding & 69 & 75 & 54 & 62 \\
\hline \multicolumn{5}{|l|}{ Feeding status } \\
\hline Exclusive breastfeeding & 60 & 69 & 49 & $65^{\star *}$ \\
\hline Breastfed within one hour of birth & 33 & $74^{* *}$ & 30 & $82^{* *}$ \\
\hline Replacement feeding & 24 & 25 & 22 & $7^{\star \star}$ \\
\hline Mixed feeding & 17 & $6^{* *}$ & 31 & 25 \\
\hline
\end{tabular}

${ }^{* *} p<0.01$

Note: significance denotes changes between baseline and endline for HIV-positive mothers and HIV-negative mothers separately.

Overall, the proportion of postpartum women giving additional foods besides breast milk decreased postintervention. Table 9 shows the detailed indicators of foods commonly used in mixed feeding.

Specifically, plain water, powdered milk, cow's milk, and other liquids were used less frequently among 
HIV-positive postpartum women; highly significant reductions were seen in the use of sugar water, soft porridge, and other solids or semi-solid foods among HIV-negative postpartum women. Significant reductions were also seen within the previous 24 hours in feeding sugar water and soft porridge among HIV-negative postpartum women.

Table 9 Infant feeding behavior by HIV status of postpartum women interviewed at the PNC clinic

\begin{tabular}{|c|c|c|c|c|}
\hline & \multicolumn{2}{|c|}{$\begin{array}{l}\text { HIV-positive } \\
\text { mother }\end{array}$} & \multicolumn{2}{|c|}{$\begin{array}{l}\text { HIV-negative } \\
\text { mother }\end{array}$} \\
\hline & $\begin{array}{c}\text { Baseline } \\
(n=114) \\
\%\end{array}$ & $\begin{array}{c}\text { Endline } \\
(n=136) \\
\%\end{array}$ & $\begin{array}{c}\text { Baseline } \\
\text { (n=162) } \\
\%\end{array}$ & $\begin{array}{c}\text { Endline } \\
(\mathrm{n}=191) \\
\%\end{array}$ \\
\hline \multicolumn{5}{|l|}{ Feeds used from birth to 10 weeks } \\
\hline Breast milk & 86 & 81 & 96 & 96 \\
\hline Plain water & 13 & $6^{*}$ & 17 & 11 \\
\hline Sugar water & 11 & 8 & 22 & $13^{*}$ \\
\hline Juice & 0 & 0 & 2 & 1 \\
\hline Tinned powdered milk & 1 & 4 & 0 & 1 \\
\hline Infant feeding formula & 25 & 21 & 28 & 20 \\
\hline Cow's milk & 3 & 0 & 2 & 1 \\
\hline Soft porridge & 13 & 7 & 23 & $8^{\star *}$ \\
\hline Other liquids & 9 & 4 & 10 & 5 \\
\hline Fruits or vegetables & 2 & 1 & 6 & 2 \\
\hline Other solids or semi-solid foods & 4 & 1 & 6 & $1^{* *}$ \\
\hline $\begin{array}{l}\text { Average number of other feeds given } \\
\text { (range } 0-10 \text { ) }\end{array}$ & 0.81 & $0.53^{* \star}$ & 1.16 & $0.63^{* *}$ \\
\hline
\end{tabular}

${ }^{*} \mathrm{p}<0.05 ;{ }^{* *} \mathrm{p}<0.01$

Note: significance denotes changes between baseline and endline for HIV-positive mothers and HIV-negative mothers separately.

\section{Follow-up Care for Mother and Infant}

\section{Knowledge of health providers on care for HIV-positive postpartum women}

Improvements were seen in the specific care health providers recommend to HIV-positive pregnant women during ANC. These improvements included encouraging early return for checkups for both mother and baby, regular monitoring of CD4 counts in the mother, and initiation of Cotrimoxazole prophylaxis for the infant (see Table 10). 


\section{Table 10 Provider recommendations to HIV-positive pregnant women in ANC}

\begin{tabular}{|c|c|c|}
\hline $\begin{array}{l}\text { Recommendations for pregnant women } \\
\text { who are HIV positive }\end{array}$ & $\begin{array}{c}\text { Baseline } \\
(n=54) \\
\%\end{array}$ & $\begin{array}{c}\text { Endline } \\
\text { (n=34) } \\
\%\end{array}$ \\
\hline Counseling on available support (general) & 26 & 29 \\
\hline Regular monitoring of CD4 count ${ }^{* *}$ & 41 & 74 \\
\hline Availability and use of ARVs & 39 & 51 \\
\hline Return for infant check in one week ${ }^{* *}$ & 24 & 51 \\
\hline Cotrimoxazole for infant from six weeks* & 19 & 43 \\
\hline Immunizations** & 4 & 40 \\
\hline Attend early postnatal care for mother** & 2 & 49 \\
\hline Cleanliness** & 0 & 34 \\
\hline Avoid stressful situations ${ }^{\star *}$ & 2 & 26 \\
\hline Eat a balanced diet** & 4 & 71 \\
\hline
\end{tabular}

${ }^{*} p<0.05 ;{ }^{* *} p<0.01$

Note: Taken from data on provider interview

Health provider knowledge or recall on the type of information they would give to HIV-positive postnatal mothers on subsequent care and support is outlined in Table 11. Most notable increases were around food supplements, family planning, support groups, and community support. Nevertheless, there is still room for improvement.

Table 11 Information on care and support that providers said they gave to HIV-positive postnatal mothers

\begin{tabular}{lcc}
\hline & $\begin{array}{c}\text { Baseline } \\
(\mathbf{n = 5 4 )} \\
\%\end{array}$ & $\begin{array}{c}\text { Endline } \\
(\mathbf{n}=\mathbf{3 4}) \\
\%\end{array}$ \\
\hline $\begin{array}{l}\text { Care and support information given } \\
\text { World food program supplements** }\end{array}$ & 11 & 37 \\
Growth monitoring for infant* $^{*}$ & 22 & 40 \\
Family planning* $^{*}$ & 30 & 51 \\
Management of opportunistic infections $_{\text {Available support groups* }}^{*}$ & 22 & 26 \\
Adherence support groups $_{\text {Community support* }}^{*}$ & 28 & 54 \\
\hline
\end{tabular}

${ }^{*} \mathrm{p}<0.05 ;{ }^{* *} \mathrm{p}<0.01$ 


\section{Counseling for HIV/PMTCT during the postnatal clinic sessions}

There were notable increases in the quality of counseling for HIV during the postnatal clinic. A quality of care index for counseling was constructed using three indicators: counseling for HIV for all postnatal mothers, and counseling and verification of the treatment received by HIV-positive postnatal mothers. The indices for each indicator are outlined below:

Counseling for all postpartum women (range 0-8): STI signs and symptoms, partner counseling and testing, information on HIV and breastfeeding, use of condom, prevention of HIV, STI/HIV risk factors discussed, presence of STI/HIV, and effects of STI/HIV during the postnatal period.

Counseling for HIV-positive postpartum women (range 0-6): Informed about Cotrimoxazole prophylaxis for infants at six weeks, infant feeding options, care and support available, informed where to get supplementary feeding for mother; informed about opportunistic infections, asked whether partner's HIV status is known.

Verification of care and treatment received by HIV-positive postpartum women (range 0-5): Given drug for PMTCT during last weeks of pregnancy; given drug for PMTCT during labor, baby received Nevirapine within three days, client received ARVs after delivery (depending on when she tested and the drug protocol), client currently on ARV treatment (if started during pregnancy), client had blood test for CD4 count since birth.

Table 12 summarizes the quality of care composite indicators that illustrate how providers discussed or counseled postpartum women on HIV and PMTCT.

Table 12 Observed counseling and treatment for prevention of PMTCT among postnatal mothers

\begin{tabular}{lcc}
\hline & $\begin{array}{c}\text { Baseline } \\
(\mathbf{n}=\mathbf{5 6}) \\
\text { Average score }\end{array}$ & $\begin{array}{c}\text { Endline } \\
(\mathbf{n}=\mathbf{1 1 7}) \\
\text { Average score }\end{array}$ \\
\hline PMTCT component & & \\
$\quad$ Counseling for all postpartum women $(0-8)^{\star *}$ & 0.92 & 3.03 \\
$\quad$ Counseling for HIV-positive postpartum women $(0-6)^{* *}$ & 0.32 & 1.03 \\
$\quad$ Treatment for HIV-positive postpartum women $(0-5)^{\star *}$ & 0.40 & 1.52 \\
Total index for HIV/PMTCT(0-19)* & 1.48 & 5.58 \\
\hline
\end{tabular}

${ }^{* *} \mathrm{p}<0.01$

Areas of improvements observed for counseling during the client-provider interactions are shown in Figure 9. 
Figure 9 Observations of providers counseling postpartum women on STIs and HIV

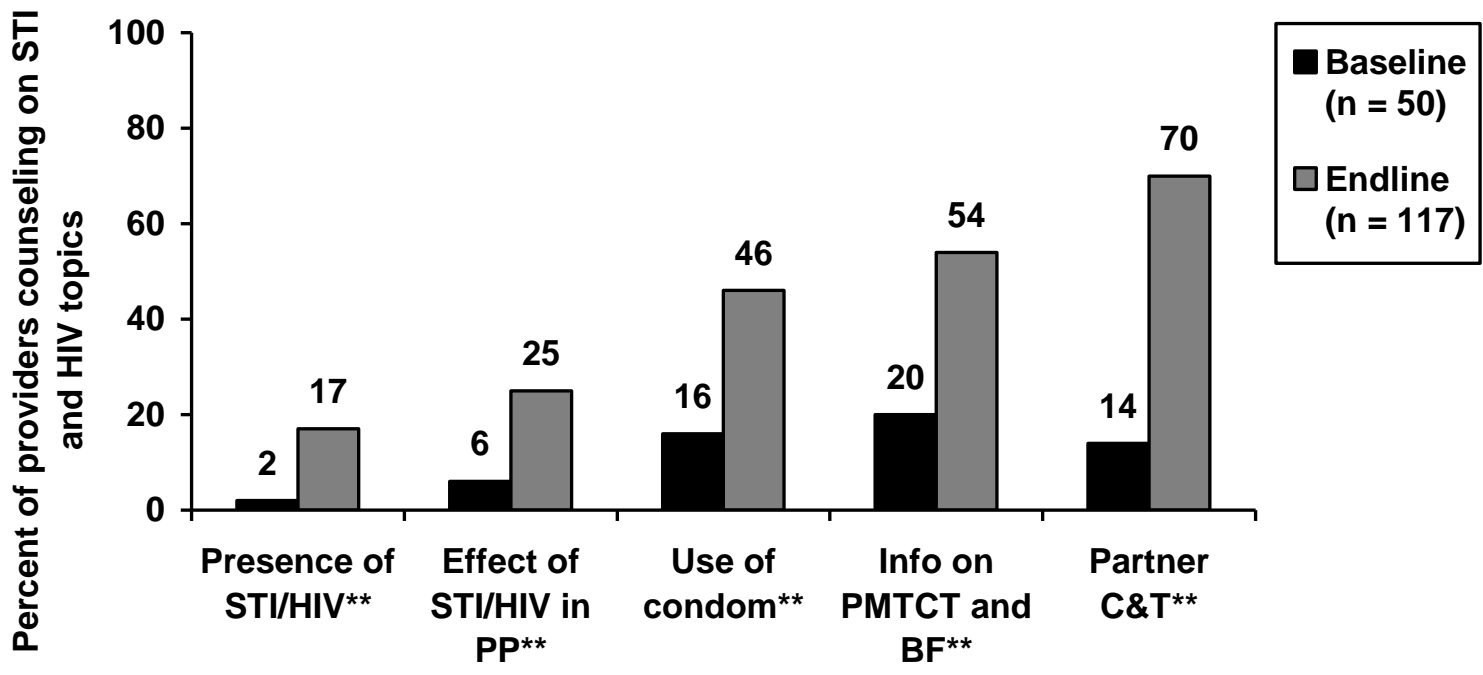

${ }^{* *} p<0.01$

Examples of the component improvements in counseling specifically for HIV-positive postpartum women include a significant increase in discussion around infant feeding options (from 6 percent to 34 percent; $p$ $<0.001$ ). Counseling on Cotrimoxazole prophylaxis for the infant increased from 4 percent at baseline to 7 percent at endline ( $\mathrm{p}<0.001$ ), specifically for postpartum women who had delivered $2-6$ weeks prior to the postnatal consultation. Health provider-led discussion on whether the partner's HIV status had been established also significantly increased (from 6 percent to 36 percent in all observed interactions; $\mathrm{p}<$ $0.001)$.

Figure 10 Counseling for HIV-positive postpartum women at postnatal clinic

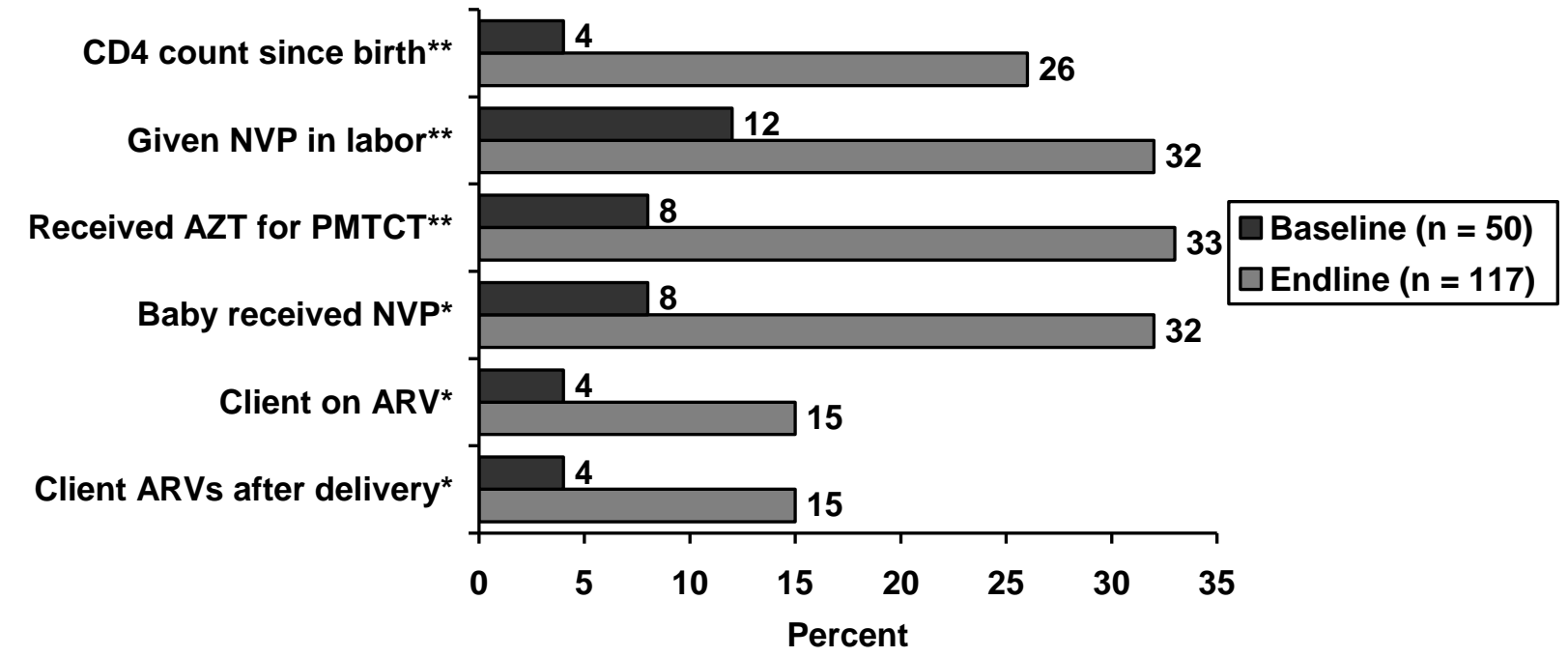

${ }^{*} p<0.05 ;{ }^{* *} p<0.01$ 


\section{HIV Testing and Disclosure}

Highly significant increases in the number of postpartum women and their partners testing for HIV are shown in Table 13. There was a notable decrease in the number of postpartum women who did not know their status (from 20 percent at baseline to 3 percent at endline; $\mathrm{p}<0.01$ ). However, there was no increase demonstrated in the proportion of postpartum women disclosing their status, which stayed the same at 86 percent.

Table 13 HIV testing behavior of postpartum women

\begin{tabular}{lcc}
\hline Indicator & $\begin{array}{c}\text { Baseline } \\
(\mathbf{n = 3 5 6 )} \\
\%\end{array}$ & $\begin{array}{c}\text { Endline } \\
(\mathbf{n}=\mathbf{3 4 6}) \\
\%\end{array}$ \\
\hline Sites where postpartum women were tested for HIV & & \\
$\quad$ Ever had HIV test** & 88 & 98 \\
Tested at VCT site & & 27 \\
Tested at ANC site $^{* *}$ & 13 & 92 \\
Tested in the labor ward $^{* *}$ & 72 & 6 \\
Tested in post-natal ward $^{* *}$ & 2 & 11 \\
Partner tested $^{* *}$ & 2 & 56 \\
Partner shared results $^{* *}$ & 28 & 34 \\
\hline
\end{tabular}

${ }^{* *} \mathrm{p}<0.01$

A percentage of postpartum women at baseline did not disclose their HIV status to their partners because they were afraid of discrimination. However, at endline this reduced significantly by almost 20 percent.

\section{Use of HIV care and support services by HIV-positive postpartum women and their infants}

There were no significant changes in the number of postpartum women given Nevirapine ( 88 percent to 90 percent) nor among those who took it during early labor ( 84 percent to 89 percent). However, there was a significant reduction $(\mathrm{p}<.05)$ in the number of postpartum women who disclosed to their partners that they had been given the drug (72 percent to 57 percent). Among postpartum women interviewed who disclosed their status as HIV-positive at endline $(\mathrm{n}=136)$, all their infants received Nevirapine within three days of birth.

Table 14 displays the significant increase in the number of newborns who received Nevirapine immediately after birth with a similar reduction of those receiving it on the day after birth. In addition, there was a significant increase noted in the proportion of both mothers and infants who had started Cotrimoxazole prophylaxis. 


\begin{tabular}{lcc} 
Table 14 Care and support for HIV-positive postpartum women and HIV-exposed infants \\
\hline Indicator & $\begin{array}{c}\text { Baseline } \\
(\mathbf{n}=\mathbf{1 1 4}) \\
\%\end{array}$ & $\begin{array}{c}\text { Endline } \\
(\mathbf{n}=\mathbf{1 3 6}) \\
\%\end{array}$ \\
\hline Other PMTCT care & \multicolumn{2}{c}{} \\
Infant received Nevirapine after birth & 82 & 86 \\
Infant received Nevirapine immediately after birth* & 60 & 74 \\
Infant received Nevirapine 1 day after birth* & 38 & 24 \\
Infant received Nevirapine 2 days after birth & 1 & 1 \\
Infant received Nevirapine 3 days after birth & 1 & 1 \\
Infant started Cotrimoxazole prophylaxis** & 13 & 37 \\
Mother started Cotrimoxazole prophylaxis** & 47 & 65 \\
Receiving care and support & 15 & 15 \\
\hline
\end{tabular}

${ }^{*} p<0.05 ;{ }^{* *} p<0.01$

Regarding the use of HIV care and support by HIV-positive postpartum women and their exposed infants, 68 percent of women said they had received information regarding support that was available. However, 29 percent of women said that they would like more information. Fifty-seven percent of the HIV-positive mothers in the postnatal ward said that they were referred for HIV support, but only five of these women had actually gone to the ARV clinic. Four out of these five women were on treatment. Sixty percent of these women said they knew they could get their infant tested for HIV at six weeks, and a further 68 percent knew about Cotrimoxazole prophylaxis. Only 54 percent said that they intended to start their baby on Cotrimoxazole. Very few women (4 in total) were advised to come back to the clinic to have their CD4 counts repeated.

The Swaziland National PMTCT Guidelines recommend that Cotrimoxazole be prescribed to HIVpositive mothers who have a CD4 count of 350, or less or WHO clinical stages ii, iii, or iv, and to all HIV-exposed infants at the age of six weeks. Of the postpartum women who recalled that their blood was taken for CD4 counts at baseline $(n=54), 59$ percent knew the result. This increased to 65 percent of postpartum women who had blood taken for CD4 $(n=89)$ who knew their CD4 count at endline.

\section{Family Planning}

When introducing the new postnatal package of care, the training mainly covered the promotion of early uptake of family planning methods and healthy timing and spacing of pregnancies. Data from the health provider interviews (baseline: $\mathrm{n}=54$; endline: $\mathrm{n}=37$ ) did not demonstrate any significant changes in recommendations of specific family planning methods to all postpartum women one week postnatal, apart from a significant drop in progestin-only pills (from 30 percent at baseline to 6 percent at endline; $\mathrm{p}<$ 0.01 ) and a drop the use of injectables (from 22 percent to 8 percent; $p=0.095$ ). There was, however, a slight increase in the proportion of health providers who said they would recommend dual protection to HIV-positive postpartum women at one week (from 30 percent to 49 percent; $p=0.072$ ). No provider mentioned lactational amenorrhea method (LAM) at baseline or endline. 


\section{Quality of counseling on family planning for postpartum women}

Family planning is a key component of prevention of mother-to-child transmission of HIV and information should be given to women at every opportunity. Newly-delivered mothers on the postnatal ward at endline were asked when they would like/would have liked to receive information about healthy timing and spacing of pregnancies and the range of family planning methods available. The responses ranged as follows: 32 percent wanted FP information in the ANC, 4 percent in the labor ward, 13 percent in the postnatal ward, 6 percent at the one week assessment, 20 percent at six weeks postnatal assessment, 11 percent said whenever the woman wanted FP, and 12 percent thought the best time for this information should be before a woman gets pregnant.

In 75 percent of the observed interactions on the postnatal ward, healthy timing and spacing of pregnancies were discussed, including the health benefits of spacing births. Improvements in counseling postpartum women in the postnatal clinic are shown in Table 15. Significantly more postpartum women were receiving information on return to sexual activity following childbirth post-intervention. Moreover, there was an increase in the proportion of observed interactions where postpartum women were advised on family planning and given information on two or more methods. For postpartum women who were more than two weeks postpartum, a substantial proportion of the interactions demonstrated an increase in the client being asked about her preferred method (from 32 percent at baseline to 82 percent at endline (p $<0.01$ ) and actually receiving her preferred method (from 28 percent at baseline to 70 percent at endline $\mathrm{p}$ $<0.01)$.

Table 15 Observed family planning integrated into PNC services among postpartum women more than two weeks after delivery

\begin{tabular}{lcc}
\hline Counseled/discussed & $\begin{array}{c}\text { Baseline } \\
(\mathbf{n = 4 7 )} \\
\%\end{array}$ & $\begin{array}{c}\text { Endline } \\
(\mathbf{n}=\mathbf{4 9}) \\
\%\end{array}$ \\
\hline Return to sexual activity $^{* *}$ & 26 & 63 \\
Advising on FP $^{* *}$ & 36 & 82 \\
Two or more methods $^{\dagger * *}$ & 28 & 61 \\
Uses anatomical models $^{*}$ & 0 & 12 \\
Uses contraceptive samples $_{\text {Provider asks which method is preferred }}^{* *}$ & 32 & 35 \\
Client receives preferred method $^{* *}$ & 32 & 82 \\
${\text { Total index score }(\mathbf{0}-\mathbf{7})^{\star *}}$ & 28 & 70 \\
\hline
\end{tabular}

${ }^{*} p<0.05 ;{ }^{* *} p<0.01$

${ }^{\dagger}$ Range of methods considered are: (1) combined pill, (2) progestin-only pill, (3) IUCD, (4) condom, (5) injectable, (6) implant, (7) bilateral tubal ligation (8) vasectomy, (9) LAM, (10) dual protection, (11) other method

\section{Postpartum women's fertility intentions}

Many postpartum women are unaware of when they could become pregnant again after giving birth. For the question related to knowledge of when a woman could expect to get pregnant again, only 8 percent of both HIV-positive and HIV-negative postpartum women at the MCH/PHU were able to give the correct 
answer of "anytime after having sex following childbirth." Sixty-nine percent of HIV-positive postpartum women and 74 percent of HIV-negative postpartum women admitted to not knowing at all. However, among the 94 postpartum women interviewed in the postnatal ward, 22 percent knew the correct answer.

The majority of postpartum women interviewed said that they did not intend to have another child. All HIV-positive postpartum women in the ward $(n=92)$ said they would be unhappy if they found out they were pregnant again. The proportion of HIV-positive postpartum women not wanting another child increased from 77 percent at baseline to 83 percent at endline, with the remaining 17 percent at endline intending to have another child after three years. For HIV-negative postnatal mothers, those who did not intend to have another child increased from 52 percent to 59 percent, and those who intended to have another child after three years decreased from 47 percent to 40 percent. The proportion of HIV-positive postpartum women interviewed exiting the clinic that had started sexual activity since childbirth remained the same at 15 percent, while the proportion of HIV-negative postpartum women who had started sexual activity reduced significantly from 12 percent to 6 percent $(\mathrm{p}<0.05)$ Twenty-eight percent of women on the postnatal ward $(n=94)$ said they intended to start sexual activity again after one week, 19 percent after six weeks, and 28 percent after six months.

\section{Postpartum women's intention to use family planning}

When postpartum women were asked when they intended to use family planning, 7 percent said now, 52 percent said they would use something in the next six weeks, and 15 percent said they would use FP in six months. Around one-fifth (19 percent) were not yet sure if and when they would use anything to prevent future pregnancies. Data from the postnatal ward exit interviews demonstrated that a number of women (47 percent) do know about LAM, but only three women (out of 94) said they intended to use this method.

Overall there was a reduction in client recall of family planning methods discussed in the postnatal clinic for both HIV-positive and negative postpartum women, with a significant reduction in the total index (from 2.88 to 2.22 out of a total of 7 methods) for HIV-positive postpartum women and a similar reduction noted for HIV-negative postpartum women (from 2.57 to 2.16 ). ${ }^{6}$ The most frequently cited family planning methods that postpartum women intended to use were the injectable, condom, and oral contraceptive pill. The most frequently used method at endline was the injectable (15 percent of HIVpositive postpartum women and 19 percent of HIV-negative postnatal mothers). Overall there was a reduction in both intention to use and actual use between baseline and endline data. Specifically condom use reduced from 14 percent to 3 percent $(\mathrm{p}<0.01)$ by endline.

\footnotetext{
${ }^{6}$ Index of seven FP methods discussed: oral contraceptive pill, IUCD, condom, injectable, implant, female sterilization, and lactational amenorrhea method
} 


\section{Acceptability of the new postnatal package}

\section{Acceptability of new postnatal package among providers}

Generally health providers appreciated the early postnatal visit. Information from group discussions included the following: those that attended the training said it was an "eye opener" that if the postpartum women and their babies are followed up with sooner, complications can be detected earlier. The early visit at one week enabled providers to reinforce feeding options, encourage postpartum women of unknown HIV status to be counseled and tested, and follow up with postpartum women who were HIVpositive. Health providers prefer to provide integrated care to the mother and infant, which includes family planning, PNC, and infant immunizations.

Among the health providers interviewed $(n=35)$ at endline, 57 percent said they had attended the postnatal training sessions; of those who did not attend, the majority (77 percent) said that their colleagues within the clinic who had attended the training disseminated information to them. Overall the elements the providers found most useful were updates on danger signs in mother and baby (90 percent), demonstration of physical examination of the mother and baby on the postnatal ward (70 percent), the contents of the PNC package (35 percent); the strengthened messages for ANC (30 percent), and the reorganization of services within the clinic (15 percent).

\section{Improved relationship between provider and client}

Overall there were significant improvements in the acceptability or satisfaction with the improved care for postpartum women measured by how they were treated in the postnatal clinic. This was measured among clients as the relationship or interactions between the provider and postpartum woman. The total index score for understanding between health providers and postpartum women in the postnatal clinics increased significantly, as shown in Table 16. Moreover, large increases (by around 50 percent) were seen in ensuring privacy and assuring postpartum women of confidentiality. Other improvements were noted as well, such as encouraging postpartum women to ask questions and whether they understood the information given. Notably there was an increase in postpartum women who had come for a one week check who were observed receiving a return appointment date for further follow up (from 86 percent at baseline to 93 percent at endline; $\mathrm{p}<0.01$ ). Among postpartum women in the postnatal ward, 99 percent thought the baby should get a check up after birth. The main reason given by most of these women (86 percent) for the check up was to monitor their infant's health and growth. 


\begin{tabular}{|c|c|c|}
\hline & $\begin{array}{c}\text { Baseline } \\
(\mathrm{n}=50) \\
\%\end{array}$ & $\begin{array}{c}\text { Endline } \\
(n=117) \\
\%\end{array}$ \\
\hline \multicolumn{3}{|l|}{ Does the provider } \\
\hline Greet the patient** & 80 & 97 \\
\hline Ensure privacy** & 52 & 99 \\
\hline Ensure confidentiality** & 36 & 74 \\
\hline Ask the client how she is feeling ** & 52 & 91 \\
\hline Look at the health card during session ${ }^{* *}$ & 74 & 94 \\
\hline Ask if any concerns/encourage questions ${ }^{* *}$ & 48 & 85 \\
\hline Ask if the client has understood everything ${ }^{* *}$ & 46 & 79 \\
\hline Give return date ${ }^{* *}$ & 86 & 93 \\
\hline Act courteous to client throughout session & 80 & 92 \\
\hline Total index score $(0-9)^{\star \star}$ & 5.54 & 8.05 \\
\hline
\end{tabular}

${ }^{* *} p<0.01$

\section{Client satisfaction and acceptability}

Postpartum women at the clinic were also asked if they could remember if/when they were asked to come in for the first postnatal visit. Mothers on the postnatal ward said they were asked to come as follows: within three days (10 percent), one week (46 percent), two weeks (11 percent), four weeks ( 2 percent), and six weeks (31 percent). Ninety-eight percent of these women expected to keep their appointment. A significant increase was noted among postpartum women who recalled that they were asked to return one week after childbirth (from 1 percent to 37 percent; $p<0.001$ ). A significant decrease was seen among the proportion of postpartum women asked to come for the first time at six weeks (from 89 percent to 27 percent; $\mathrm{p}<0.001$ ). There were no changes noted for postpartum women saying they were asked to come for a postnatal check up while they were still pregnant. Ninety-eight percent of postpartum women considered the postnatal visits important (14 percent within three days after birth and 47 percent within one week). 


\section{Discussion}

This study, one of the few in sub-Saharan Africa to look at comprehensive postnatal care, confirms that the introduction of an improved postnatal package with revised timing and content provides key components of maternal, newborn, and HIV care, and increases the utilization of services among postpartum women and their infants. Postpartum women are three times more likely to seek PNC within one week of delivery. Assessment of the quality of care for postpartum women and their infants during the postnatal consultations demonstrated a fourfold increase in the proportion of observed interactions that included all aspects of care: maternal and newborn health, counseling for HIV, family planning, and good client-provider relationships.

The increased acceptability by providers and clients alike of the new postnatal package of care suggests that it is feasible to strengthen maternal and newborn care in a high HIV environment within the constraints of a weak health system. Integrating MNH, HIV/AIDS, and PMTCT services within a comprehensive postnatal package can ensure adequate quality of care without compromising either $\mathrm{MNH}$ or PMTCT.

The new postnatal package focuses on both the timing and content of care for mother and infant. The design of the services stipulates that the mother and the newborn should be cared for by the same provider at the same encounter within 48 hours, one week, and six weeks. The inclusion of the pre-discharge package of care (within 48 hours) assures that the mother and infant are carefully evaluated by a health provider before they leave the postnatal ward; this represents an excellent opportunity to identify and address problems, to counsel on essential care, and to identify and act on any danger signs. The postnatal consultation within 3-7 days also provides an excellent opportunity to assess infant feeding and essential obstetric and newborn care, as well as to reassure the mother. By strengthening the content of the six week consultation, the quality of care increased, resulting in improvements in immunizations, family planning uptake, and care and follow up for both HIV-positive and HIV-negative postpartum women and their infants.

Care for the mother and baby should include a thorough assessment (history taking, physical examination, and diagnostic tests as appropriate), provision of care (prophylactic and curative treatments and referrals as required), and effective counseling.

\section{Maternal and Newborn Health}

Antenatal care provides a platform for the continuum of care through the postnatal period and beyond. While the PMTCT activities appear to be strong in ANC as a result of the influence of the national PMTCT program, essential elements of maternal and newborn health care are lacking. Although results indicate that counseling in ANC around labor and childbirth improved, there was minimal discussion on important elements in the postnatal period. Specifically, pregnant women were not warned about the danger signs post-delivery for the mother or the newborn, nor were they counseled on infant feeding and family planning. The limited information given to women during the $8^{\text {th }}$ month of gestation is a missed opportunity for emphasizing available services in the postnatal period.

Nevertheless, more health providers at endline were observed advising pregnant women to come back for checkups within one week after childbirth. If postpartum women do attend ANC at least four times, they 
are more likely to opt for a skilled attendant at delivery and to return for postnatal care. This resonates with data from the DHS comparative report from 15 countries on postnatal care in developing countriesthe likelihood of attending PNC rises with increased number of ANC visits (Fort et al.. 2006).

\section{Essential obstetric and newborn care}

Evidence from several African studies shows that mortality among HIV-positive postpartum women is high in the post-pregnancy period (McIntrye 2005) and that their newborns are particularly vulnerable during the first few days after birth, specifically from non-HIV related causes. Key elements of essential preventive care for the mother and infant can significantly reduce mortality in the early postnatal period. In this study health providers showed improvements in their knowledge and skills on basic postnatal care.

One of the most challenging findings in this evaluation was that postpartum women were not always able to recall information given to them during the postnatal consultations. Despite the fact that there was a significant increase in health providers paying particular attention to counseling on key messages on essential care and danger signs in the postnatal period, there were only small increases in postpartum women able to recall two signs of complications for both the mother and infant in some instances.

Based on BASICS earlier work in Senegal ${ }^{7}$, it is possible that mothers' recall would be improved by (a) reinforcement of messages through additional persons such as less-skilled trained health providers or counselors at the facility level and community health workers using tools such as counseling cards, and (b) through additional methods such as interpersonal communications and mass media. It is also important to improve the counseling skills of all categories of health workers; merely informing mothers and families may not be enough, and time needs to be spent on negotiating the desired healthy behaviors.

The age profile of infants brought to the clinic during the survey period reflects that mothers are indeed adhering to the revised timing of the first postnatal visit at one week. Initially, health care providers were hesitant about promoting the visit within three days, but utilization of the services between three and seven days did increase. Utilization data shows a 20 -fold increase in the number of first visits within three days at endline. This is evident among all postpartum women regardless of HIV status. Possible factors resulting in the above were (a) counseling in ANC of the importance of early postnatal care, and, probably of greater importance, (b) additional counseling and giving a specific appointment for the visit at discharge of the mother and baby from the facility after delivery.

Due to time limitations and to the fact that by $\mathrm{MOH}$ mandate, treatment of postnatal complications in the mother and the baby is done by physicians in Swaziland, the training focused on identification of danger signs by the midwives and nurses and immediate notification to the physician (or referral from the clinics to the hospitals) for treatment. Improvement in knowledge regarding certain aspects of the management of complications can be caused by motivation for self-learning by the providers using the materials that were distributed during the training.

\section{Infant feeding}

Breastfeeding is culturally a part of Swazi life, but the HIV epidemic has created some confusion, as feeding recommendations have changed over the last decade. Ideally, counseling on feeding, including

\footnotetext{
7“Newborn interventions in Senegal-The early implementation phase," Ndoye et al., 2004, Arlington, VA.
} 
discussions on infant feeding options for the HIV-positive mother, should be an essential topic during the whole ANC period. The mother is then prepared as soon as delivery has occurred to prevent unnecessary delays in the initiation of breastfeeding. Early and exclusive breastfeeding remains a challenge for both providers and postnatal mothers, even though there was a significant increase in the proportion of postpartum women initiating breastfeeding within one hour. Still, only 4 out of 10 providers talked about exclusive breastfeeding following the intervention. Nevertheless, more health providers said they would observe that proper feeding was taking place in the postnatal ward before discharge. More providers were observed giving breastfeeding information and support to postpartum women in the clinics.

Few postpartum women could recall receiving information on infant feeding on the antenatal ward or in the maternity unit, and some mothers were still not encouraged to put their newborns to the breast at birth in the delivery ward. While many new mothers are able to breastfeed their infants within one hour, most of these have to walk to the postnatal ward with minimal assistance first. Significant reductions were seen in the frequency of mixed feeding. All postpartum women were less likely to give their infants alternative feeds to breast milk.

\section{Follow-up care and support services for mother and infant}

Improvements in HIV/PMTCT services during ANC can be attributed mainly to the MOHSW national PMTCT program. Nearly all postpartum women reported knowing their HIV status. It is of no surprise that there continues to be a high proportion of pregnant women testing for HIV during ANC. But as a result of strengthening postnatal care, around one-sixth of pregnant/early postnatal women were tested in the labor and postnatal ward at endline.

More women are receiving ARV prophylaxis during pregnancy (AZT) and Nevirapine during early labor, with a high proportion of newborns receiving Nevirapine at birth. More infants receive Nevirapine immediately after birth or within one day; this demonstrates prompt action by health care providers to ensure that all infants receive Nevirapine.

One challenge for both health providers and HIV-positive women is the fact that the antiretroviral drug regimens for PMTCT of HIV are constantly changing. Even within the time frame of the study (15 months, from February 2006 to May 2007), the regimen for postpartum women receiving Nevirapine in early labor has been augmented by AZT from 28 weeks followed by AZT for up to four weeks postdelivery for the infant, depending on when the woman started AZT.

There were notable improvements in the uptake of Cotrimoxazole prophylaxis by both mother and infant. Slightly less than 5 in 10 mothers were on Cotrimoxazole at baseline compared to 7 in 10 mothers at endline. Four in ten HIV-exposed infants were on Cotrimoxazole prophylaxis at endline compared to one in ten infants at baseline. In Swaziland the PMTCT guidelines emphasize that Cotrimoxazole is prescribed to HIV-positive mothers who have a CD4 count of 350 or less or WHO clinical stages ii, iii, or iv, and to all HIV-exposed infants at six weeks.

After the intervention, health providers gave more information to HIV-positive women on available care and support. This included information and counseling on food supplements, family planning, support groups, and community support. In addition, observations of the postnatal consultations demonstrated increased counseling on available services and STI/HIV risk factors. More providers confirmed that HIVpositive postpartum women received the relevant or appropriate follow-up care and treatment. By 
improving the timing and content of the postnatal package, increases were noted in the use of the support by HIV-positive postpartum women.

\section{Family Planning}

Discussions on healthy timing and spacing of pregnancies and number of children wanted are crucial to prevent unplanned or unwanted pregnancies. In addition, optimal birth spacing intervals of three years between pregnancies are also associated with significantly lower maternal and neonatal morbidity and mortality. Pregnancy intervals shorter than six months are associated with increased risk of maternal anemia, premature rupture of membranes, low birth weight, and pre-term delivery.

Although family planning was not covered in depth during the training, it is recognized as an integral part of the postnatal care package. Strengthening the overall package of care resulted in a ripple effect and appeared to stimulate health providers to improve care in other areas. This resulted in an increase in discussions and uptake of FP. Notably, health providers asked postpartum women which FP method they preferred and also provided the preferred method. However, a high proportion of postpartum women do not seem to know when fertility returns following childbirth. Many postpartum women do not want another child and yet do not utilize or are not necessarily intending to use any FP methods. These findings are consistent with preliminary results from the preliminary report of the Swaziland DHS 2006-07 and similar studies currently underway in Lesotho and Kenya (Warren et al 2007, Warren and Mwangi 2008).

\section{Service Delivery}

Building good relationships between provider and client is a necessary aspect of good service delivery and will enhance acceptability and therefore increase utilization of services. Using postpartum women's motivation to protect their new offspring provides an incentive for behavioral change (McIntyre 2005). While time may not be on the side of the providers, listening to postpartum women is an essential element in the provision of flexible and responsive postnatal care that meets the needs of postpartum women and families (Butchart et al. 1999).

The introduction of the intervention activities themselves was feasible, but problems were encountered that may influence the clinics' capacity to implement and sustain the re-organized services, including trainer and staff turnover, inadequate logistics and budgetary planning, and insufficient involvement of key stakeholders.

Since the inception of the national PMTCT program in 2003, phased integration of activities into existing $\mathrm{MCH}$ services is gaining momentum. The changes to additional care in the postnatal period including the extra visit at one week has strengthened the follow-up of all postpartum women and infants after delivery.

The post-intervention improvements in quality of care provided from ANC through the postnatal period and acceptability by postpartum women suggests is it feasible to strengthen the continuum of care from pregnancy through six weeks postnatal in a high HIV environment within the constraints of a weak health system. 


\section{Scale Up}

The MOHSW and partners have already started replicating parts of the intervention. Selected health providers from non-intervention sites participated in the PNC training sessions. Some of these health providers were inspired to replicate the PNC package in Hlatikulu PHU, and the MOHSW asked BASICS to make two supervisory visits to assess the postnatal care services in that facility. This demonstrates that where there is commitment, postnatal services can be strengthened with minimal input.

However, efforts to scale-up or replicate this model throughout the country and elsewhere in the southern African region must consider resource issues during the planning and budgeting phase. Moreover, other support systems, such as staff supervision and educational materials, need attention alongside strengthening more obvious systems such as training, equipment, and supplies. In addition to the training materials and job aids developed for the intervention, the introduction of parent-baby leaflets and other IEC materials may help improve understanding of postnatal care.

If interventions rely heavily on training staff in new ways of organizing and providing services, additional support is required. Training and supervisory strategies or systems must be designed to incorporate relatively rapid rates of staff turnover and made available as on-site training. This may mean developing the capacity of the clinic staff, or of the supervisor responsible for monitoring PNC services in the clinic, to ensure that if a trained staff member leaves the unit, the replacement health provider either has the same technical competence or undergoes immediate training in PNC. Health providers need to fully understand their new roles in reproductive health programs to enable them to perform their new jobs effectively and to discourage them from reverting to their former practices.

Knowledge and skills of health care providers improved significantly; however, there are still a number of gaps in providing comprehensive antenatal and postnatal care. It is important that sufficient nurse/midwives are updated in the PNC package to continue the progress made so far.

The investment from the PMTCT programs to the health facilities should not be lost through inadequate basic maternal and newborn health care and follow up.

\section{Recommendations}

\section{Strengthen policy guidelines related to care of the mother and the baby}

- Policies related to the continuum of care for maternal, newborn, and infant health should be strengthened from the pre-pregnancy to the postnatal periods and linked to HIV/PMTCT strategies.

- Finalize and scale up The Postnatal Guidelines across the country. All training materials and job aids developed by MOHSW and BASICS may be formally adopted for scaling up postnatal care.

- Develop policy guidelines for training, supervision, monitoring, and evaluation, and strengthen the procurement of essential equipment and supplies.

- Use antenatal care as a platform for women to receive relevant information and care on pregnancy, childbirth, and the immediate postnatal period (especially advocacy for the first few days after childbirth).

- Strengthen PNC linkages at the facility and community levels and institutionalize the new minimum package of postnatal care (see Box 1). 


\section{Develop and implement a plan to strengthen health systems}

- Strengthen or develop an integrated training strategy that links reproductive health; maternal, newborn, and child health; and HIV components, giving special attention to gaps in areas identified during the intervention

- Reposition family planning with an emphasis on healthy timing spacing and limiting pregnancies to improve health outcomes for the mother, the baby, and their family.

- Strengthen in-service training/updates and supportive supervision - involve all cadres: doctors, nurse midwives, assistants, and community health workers (CHWs).

- Review and strengthen pre-service curriculum and training on essential maternal and newborn care, including PNC. Emphasis should be placed on the elements that can be expected to have the greatest public health impact.

\section{Box 1 Postnatal package of care}

- Focused, early postnatal care is both feasible and acceptable in a high HIV environment.

- It is critical to provide quality of care at the place of delivery (facility or home); careful assessment before the attendant leaves after home deliveries or before discharge after facility deliveries; and counseling on essential preventive care, early postnatal visits (including giving an appointment), and identification and care-seeking for danger signs. Therefore, ideal follow-up schedules are:

- Discharge within 24 hours: Visit at the postnatal clinic by day 3 after birth, or home visit by a CHW within next 24 hours. Repeat visit by day 7 after birth and/or in the second week after delivery when necessary.

- Discharge by day 3-7: Link with a CHW for a home visit within 3 days of discharge and repeat home visit at facility in the second week when necessary.

- An additional visit is recommended at 4-6 weeks after birth

- Other situations such as low birth weight and complications around the time of the delivery might require additional postnatal visits.

- The content of the postnatal package must integrate all preventive aspects of MNH, HIV/AIDS including PMTCT, and family planning services in one comprehensive consultation for the postnatal mother and her baby.

- The facilitation of the necessary system's processes (organizational changes), such as allocation of staff, availability of physical space and equipment/supplies, and efficient client flow, is key for the adequate provision of the newly repositioned postnatal services.

- The continuity of quality of postnatal services should be ensured with strategies such as supportive supervision. 


\section{Community-based interventions}

- Strengthen the capacity of available human resources such as RHM trainers, RHM, and other CHWs on postnatal care and forge strong linkages with health facilities

- Suggested roles for the RHM on MNH activities include the provision of counseling during home visits and community mobilization activities on preventive aspects of care, identification of danger signs, and appropriate care-seeking during the antenatal and postnatal periods for the mother and baby.

\section{Communications strategy}

- Effective strategies for communication related to healthy behaviors on MNH care are essential at both facility and community levels, including strengthening of counseling and negotiation skills of the health workers. While health providers need to develop these skills, they might be busy and not have enough time; the support of less-skilled workers that have been appropriately trained might be helpful.

- Strengthen communication techniques such as the use of counseling cards

- Repetition through multiple approaches such as interpersonal communication, mass media, and traditional methods can also provide support to strengthen messages.

\section{Strengthen monitoring and evaluation}

- Document all activities. Tools developed for the intervention include all key information relevant to the care of the mother and the baby

- Review maternal and newborn health registers: Additional columns were added to delivery room and postnatal clinic registers, and need to be revised based on the findings of the project. Registers should be available in the delivery room, maternity ward, and the postnatal clinic. For care before discharge, separate registers may be needed in large maternity units, or a common register with the delivery room may be sufficient for smaller unit

- Improve quality of reporting. Review data collected at the local sites periodically to see trends and determine changes necessary to improve services. 


\section{References}

Butchart, W.A., B.L. Tancred, and N. Wildman. 1999. "Listening to women: focus group discussions of what women want from postnatal care," Curationis 22(4): 3-8.

Department of Health, South Africa: 2003. National Committee on Confidential Enquiries into Maternal Deaths. Saving Mothers 1999-2001. Pretoria: DOH.

Fort, Alfredo L., Monica T. Kothari, and Noureddine Abderrahim. 2006. "Postnatal care: Levels and determinants in developing countries." Calverton, Maryland: USA Macro International Inc.

Gray, Glenda and James McIntyre. 2005. "HIV and pregnancy," British Medical Journal 334: 950-953.

Kober, Katharine and Robert Van Damme. 2006. "Public sector nurses in Swaziland, can the downturn be reversed?," Human Resources for Health 4(1): 13.

Lawn, Joy.E., Simon Cousens, and Jelka Zupan for the Lancet Neonatal Survival Steering Team.2005.

"Neonatal survival 1: 4 million neonatal deaths: When? Where? Why?," The Lancet 365(9462): 891-900.

Lewis, G. 2004. "Confidential enquiries into maternal deaths: beyond the numbers: reviewing maternal deaths and complications to make pregnancy safer." Geneva: World Health Organization.

McIntyre, James. 2005. "Maternal health and HIV," Reproductive Health Matters 13(25): 129-135.

Ministry of Health and Social Welfare Swaziland. 2006. PMTCT of HIV Guidelines Second edition. Mbabane: MOHSW.

Myer, L. et al. 2005. "Focus on postnatal women: Linking HIV care and treatment with reproductive health services in the MTCT-plus initiative," Reproductive Health Matters 13(25): 136-146.

Narayanan, I. et al. 2004a. "The components of essential newborn care.” Arlington, VA: BASICS II (for the United States Agency for International Development).

Narayanan, I. et al. 2004b. "Safeguarding investment in PMTCT programs by incorporating essential newborn care.” Arlington, VA: BASICS II (for the United States Agency for International Development).

Ndoye, Adama et al. 2004. "Newborn health interventions in Senegal: The early implementation phase." Senegal and Arlington, VA: MOH (Senegal), and BASICS II (for the United States Agency for International Development).

Reynolds, H. W. Wilcher. 2006 "Best kept secret in PMTCT: Contraception to avert unintended pregnancies," AIDSlink (97): 8-9.

Rutenberg, N. et al. 2003. "Evaluation of a United Nations-supported pilot projects for the prevention of mother-to-child transmission of HIV." New York: UNICEF and Population Council. 
Rutenberg, N. and C. Baek. 2004. "Review of field experiences: Integration of family planning and PMTCT services." Washington, DC: Population Council.

Swaziland Central Statistical Office and Measure DHS 2007. Swaziland Demographic and Health Survey 2006-07 Preliminary Report. Central Statistical Office ,Ministry of Economic Planning and Development Mbabane Swaziland and Macro International Calverton MD USA

Sweat, M. D., et al. 2004. "Cost effectiveness of nevirapine to prevent mother to child transmission of HIV in eight African countries," AIDS 18(12): 1661-1671.

Warren, Charlotte et al. 2007. "Extending prevention of mother-to-child transmission through postpartum family planning in Lesotho," FRONTIERS Final Report. Washington, DC: Population Council.

Warren, C., A. Mwangi, and N. Koskei. 2008. "Population Council and ACCESS -FP," unpublished.

WHO 2005. "Make every mother and child count," World Health Report. Geneva, Switzerland: World Health Organisation. 


\section{Hgrizons}

Horizons is a global operations research program designed to:

- Identify and test potential strategies to improve HIV/AIDS prevention, care, and support programs and service delivery.

- Disseminate best practices and utilize findings with a view toward scaling up successful interventions.

\section{P Population Council}

Horizons is implemented by the Population Council in collaboration with

- International Center for Research on Women (ICRW)

- International HIV/AIDS Alliance

- PATH

- Tulane University

- Family Health International (FHI)

- Johns Hopkins University

For more information, please contact:

Horizons Program, Communications Unit 4301 Connecticut Avenue, NW Suite 280 Washington, DC 20008 USA

Tel: 202-237-9400

Fax: 202-237-8410

Email: horizons@popcouncil.org www.popcouncil.org/horizons 